\title{
WestVirginiaUniversity
}

THE RESEARCH REPOSITORY @ WVU

Graduate Theses, Dissertations, and Problem Reports

2014

\section{Conceptual Learning: Enhancing Student Understanding of Physiology}

Micah J. Waltz

West Virginia University

Follow this and additional works at: https://researchrepository.wvu.edu/etd

\section{Recommended Citation}

Waltz, Micah J., "Conceptual Learning: Enhancing Student Understanding of Physiology" (2014). Graduate Theses, Dissertations, and Problem Reports. 493.

https://researchrepository.wvu.edu/etd/493

This Thesis is protected by copyright and/or related rights. It has been brought to you by the The Research Repository @ WVU with permission from the rights-holder(s). You are free to use this Thesis in any way that is permitted by the copyright and related rights legislation that applies to your use. For other uses you must obtain permission from the rights-holder(s) directly, unless additional rights are indicated by a Creative Commons license in the record and/ or on the work itself. This Thesis has been accepted for inclusion in WVU Graduate Theses, Dissertations, and Problem Reports collection by an authorized administrator of The Research Repository @ WVU. For more information, please contact researchrepository@mail.wvu.edu. 


\title{
Conceptual Learning: Enhancing Student Understanding of Physiology
}

\author{
Micah J. Waltz \\ Thesis submitted \\ to the \\ School of Medicine \\ at West Virginia University \\ In partial fulfillment of the requirements \\ for the degree of \\ Master of Science \\ in \\ Biomedical Sciences \\ Robert W. Brock, Ph.D., Chair \\ Stanley M. Hileman, Ph.D. \\ Mark A. Paternostro, Ph.D. \\ Department of Physiology and Pharmacology \\ Morgantown, WV \\ 2014
}

Keywords: conceptual learning, science education, physiology education, learning with multimedia

Copyright 2014 Micah J. Waltz 


\title{
Abstract \\ Conceptual Learning: \\ A Tool to Enhance Student Understanding of Physiology
}

\begin{abstract}
Micah J. Waltz
Students are leaving undergraduate science programs without the knowledge and skills they are expected to have. This is apparent in professional programs, such as medical and veterinary school, where students do not possess the critical thinking skills necessary to be successful. Physiology is a required discipline for these professional programs and often before, as a prerequisite. Physiology classrooms are an excellent place to teach critical thinking skills because the content consists of integrated processes. Therefore, in one study, it was investigated whether focusing on physiological concepts improved student understanding of physiology in both a nonphysiological science course, Invertebrate Zoology, and in an undergraduate physiology course. An educational intervention was used in Invertebrate Zoology, where students were exposed to human physiology concepts that were similar to comparative physiology concepts they had learned during the semester. A pre-/post-test was used to assess learning gains. In a second study, the use of multimedia file usage was correlated to student exam scores in a physiology course. This was done to see if providing additional study materials that focused on specific concepts improved student understanding, as assessed using exam scores. Overall these studies indicate that encouraging assimilation of new concepts that expand upon material from lecture may help students gain a more complete understanding of a concept. The integration of these concepts into pre-existing conceptual frameworks may serve to teach students valuable critical thinking skills such as evaluation of new ideas within their current understanding and synthesizing the new content with the existing information. Focusing on this type of conceptual learning may enable students to apply content knowledge and think through problems. Additionally, focusing on concepts may enable students to improve their understanding of material without being overwhelmed by content.
\end{abstract}




\section{Acknowledgements}

I would like to acknowledge the people without whom this thesis would not have been

completed. First, I would like thank my committee members, Drs. Rob Brock, Stan Hileman, and Mark Paternostro. Rob has been invaluable through the labyrinthine changes my graduate career traversed; he was always available to help with anything I needed, including listening. Stan has been a wonderful mentor. I have fond memories of discussing endocrinology with him. Mark has been both a teaching and personal mentor to me, and I would not be here without the opportunities to work with him that I have had. Mark was also gracious enough to provide part of the assessment I used in this thesis. I also want to acknowledge Dr. Katrina Stewart, my other teaching/personal mentor, who has always been encouraging and offered insight as well as statistical advice when necessary. Dr. Tracy Becker not only contributed pharmacy questions to the assessment, but has also been there for me through the ups and downs of graduate school. I would like to thank Dr. Jessie Peck for contributing the veterinary questions for the assessment, being available to discuss research in her field, and being a wonderful role model to grow up with. I would like to acknowledge Dr. Kay Walter for being both a writing and personal mentor as well as for her inspiration and encouragement through this time. I would like to acknowledge Raederle Clay, who started on this journey with me when I was an undergraduate and has been a supportive friend and IT guru throughout this process. Finally I would like to acknowledge my fellow graduate students who have stood by and supported me during this process. Robin Cline is an amazing fount of information, about parametric and nonparametric statistical analyses, as well one of the most supportive people I could ever have as a friend. She sat next me when I was struggling to write sections of this document and would gently push me back down when I tried 
to walk away. Nick Wilbur not only facilitated this project in the classroom to make this a blind study, he has always been available for questions, comments, concerns, griping, and the best running partner I could ask for. Last, but most certainly not least, Helen Rodgers has been my family here at WVU, walking beside me every step of the way. 


\section{Table of Contents}

Abstract.................................................................. ii

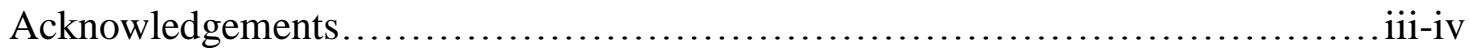

Table of Contents.................................................... v-vi

List of Tables and Figures............................................... vii

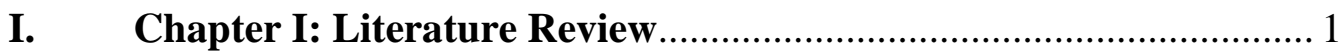

a. Shifting Focus in Medical Education................................ 3

b. Shifting Focus in Veterinary Education........................................... 9

c. Shifting Focus in Undergraduate Education.................................. 13

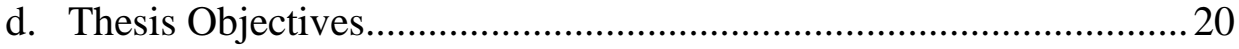

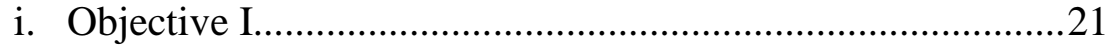

ii. Objective II................................................................. 22

II. Chapter II: Methodological Approaches.....................................2 23

a. Objective I................................................. 24

i. Educational Intervention............................. 24

ii. Class Setup ............................................ 24

iii. Class Demographics................................25

iv. Assessments................................................................ 25

v. Pre- and Post- Test....................................................... 26

vi. Pre- and Post- Questionnaire .............................................. 26

vii. Quantitative Analyses ................................... 27

viii. Statistical Analyses................................ 27

b. Objective II.............................................. 28

i. Class Demographics............................... 28

ii. Data Processing....................................... 28

iii. Statistical Analyses....................................... 29

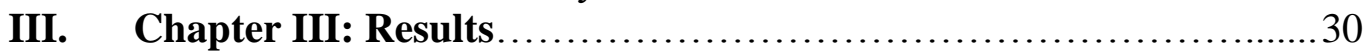

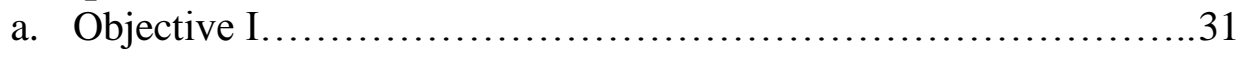

i. Learning Gains.......................................... 31

ii. Student Perception....................................... 32

b. Objective II............................................. 33

i. Overall File Access.................................... 33

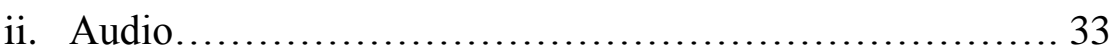

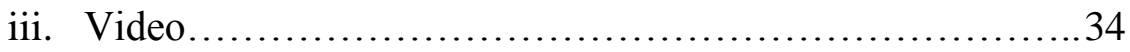

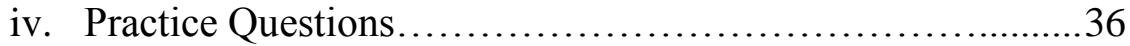

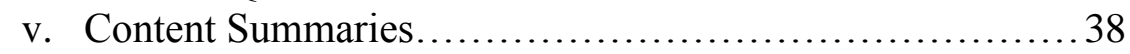

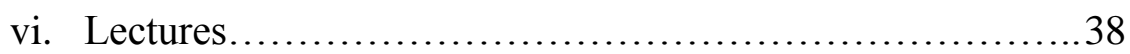

IV. Chapter IV: Discussion and Future Directions....................41

a. Discussion............................................... 42

i. Physiology Education Intervention in a Basic Science Classroom......................................... 45 
ii. The Effects of Focusing on a Multimedia Approach in a Physiology Classroom................................... 48

b. Future Directions......................................... 51

i. Physiology Education Intervention in a Basic Science Classroom.................................................. 51 The Effects of Focusing on a Multimedia Approach in a Physiology Classroom................................... 53

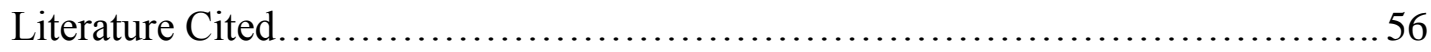

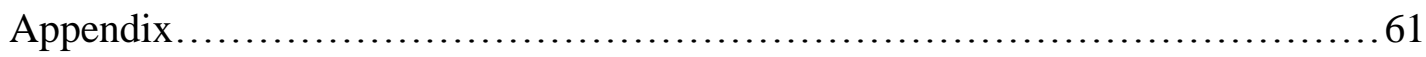

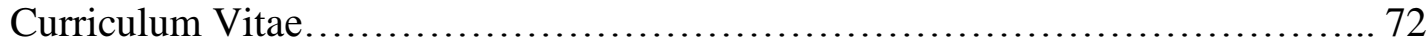




\section{List of Tables and Figures}

\section{Chapter III: Results}

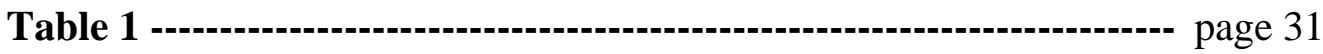

Summary of Averages and Standard Errors for Learning Gain

Question Categories

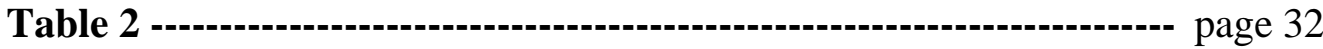

A Summary of Descriptive Statistics for Learning Gains Calculations by Student.

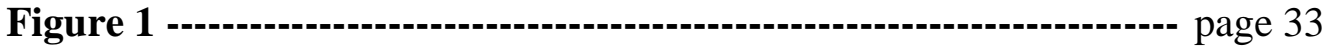

Association of Learning Gains with the Change in Student

Self-Confidence.

Figure 2 page 34

Correlation of Number of Times Summed Files from Course Website were Accessed with the Average of Student Exam Scores

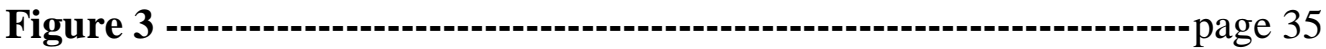

Correlation of the Number of Times Audio Files were Accessed with Student Exam Scores.

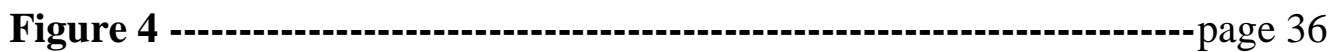

Correlation of the Number of Times Video Files were Accessed with Student Exam Scores

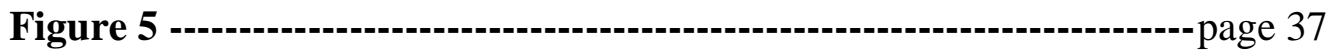

Correlation of Number of Times Practice Questions were Accessed with Student Exam Scores.

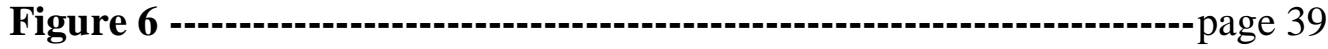

Correlation of Number of Times Content Summary Files were Accessed with Student Exam Scores.

Figure 7 -----------------------------------------------------------page 40

Correlation of the Number of Times Lecture Files were Accessed with Student Exam Scores. 
Chapter 1:

Literature Review 


\section{Introduction}

Clinicians are extensively educated before they are licensed and allowed to practice. Students intending to go into professional fields are encouraged to choose a science undergraduate degree that optimally prepares them for the rigors of professional programs. The explosion of knowledge gained from biomedical and basic science research in the last century has resulted in the requirement for learning an overwhelming amount of content in science courses (Cooke et al. 2006, Zheng et al. 2008). Students are required to memorize extensive lists of knowledge that are then tested; exams drive students learning (Cooke et al. 2006). This kind of learning is not translating to skills identified as necessary for graduate and professional programs such as medical and veterinary school (Flexner, 1910; Pew Report, 1989; Zheng et al. 2008). Traditional measurements of academic success (i.e. standardized exams) do not adequately measure students' capabilities to problem solve, evaluate, analyze, and synthesize information (Bloom et al. 1956, Krathwohl et al. 1964, Krathwohl 2002, Crowe et al. 2008). These critical thinking skills, or competencies, have been challenging to convey to students because they are difficult to assess. These competencies are considered taught and learned when, according to the American Association of Medical Colleges (AAMC), the students repeatedly demonstrate their use and application to various types of scenarios integrating information across various disciplines (AAMC, 2009). To promote the early development of these skills within classrooms the most recent medical education review assesses pre-medical students on the scientific process and other competencies to ensure students are better prepared for professional fields with critical thinking skills and content knowledge (Brouet et al., 2013). These competencies are better representations of the mental processes doctors are required to have than the current MCATs. Undergraduate science education is emphasizing teaching concepts as well 
as content, in an attempt to teach students valuable critical thinking skills (AAAS, 2011; Tanner and Allen, 2004). The competencies being emphasized by the revised MCATs are similar to the concepts being focused on in the undergraduate science reforms. These are generalizable across disciplines and content can be integrated into the teaching of these competencies/concepts. This sort of learning is known as conceptual learning. There are two phases of conceptual learning students may go through. The first phase, assimilation, is when students are capable of using information they already know to process new concepts. The second phase, accommodation, is when students' current understanding of a concept renders them unable to interact with the new concept effectively, resulting in restructuring of the intellectual framework or replacing an old concept with a new one (Posner et al. 1982).

\section{Shifting Focus in Medical Education}

Medical education is designed to train medical students to become clinicians that provide the best patient care possible (Cooke et al. 2006). As the medical profession has evolved over the past century, public expectations of patient care from diagnosis to recovery have increased (Calman, 1994; Cooke et al. 2006; Flexner, 1910). The nature of medicine has become exponentially more complicated since the development of molecular research in the 1960s, leading to increasingly complicated treatment protocols, such as occurs in cancer treatments (Cooke et al. 2006). Medical education is evolving to keep up with the increasing volume of knowledge generated in basic and biomedical sciences. One major of focus is the integration of disciplines during, and before, medical school curricula to also teach students valuable critical thinking skills (AAMC, 2009; Alpern, 2011).Other changes that are being revived in medical education are restructuring preceptorships and apprenticeships and changing the structure of how and when certification for specializations is obtained (Cooke et al. 2006; Goldman, 2004; 
Pellegrini, 2004). Restructuring specializations is designed to not only decrease the time medical students are learning non-essential information for their specialization, but to create a more structured educational environment where students are consistently mentored over the course of their specialization by medical professionals (Cooke et al. 2006; Goldman, 2004; Pellegrini, 2004; Sachdeva, 1996). Moreover, medical education has begun to emphasize evidence-based practice, where an individual's clinical experience is informed by external clinical and basic science research to provide patients with the current best options ("Evidence Based Medicine," 1992; Sackett et al. 1996). By using evidence based medicine the medical school curriculum is ensuring students are learning the fundamental competency of the scientific process (AAMC, 2009). This is an example of the curriculum addressing the need to teach students critical thinking skills. The scope of current practices in medical education has needed to expand to also include the political, social, and economic aspects of medicine (Cooke et al. 2006; Moskowitz and Thompson, 1999). The revised version of the MCATs for 2015 includes sections on cultural diversity and awareness to ensure doctors are being trained adequately to function in a global society (Mededportal iCollaborative page, 2014).

Since most patients can reasonably expect survival, the clinician is now expected to focus more on the quality of life, treating symptoms and being aware of social difficulties any pathology could cause (Brody, 1980; Petri and Kolbl, 2004). With increasing access to the global community, clinicians are seeing patients from different ethnic backgrounds, increasing the possibility these social stigmas may be fueling political policies and agendas (Al-Krenawi, 2005). Treatment of mental illness in countries such as China and Russia has been used to oppress people expressing dissenting opinions to the political regime of the time (Al-Krenawi, 2005). Hospitals and medical treatments are becoming increasingly rationed by access and 
finances. Medical practice has become increasingly driven by money, leading to a need for the clinician to see more patients. This ultimately hinders medical treatment as the physician must spend less time per patient (Brown, 1979; Sturdy, 1992). Medical students must be trained, not only in the science of medicine, but also in the art of interacting and communicating with people from various ethnic and religious backgrounds (Lane, 2010; O'Callaghan, 2013). Their education must prepare medical students for situations where medical practice can be compromised by any combination of social, political, and economic issues.

In the initial medical curricula reform (Flexner, 1910), there are two main themes emphasized while training future physicians. First, medical students need to gain a strong didactic knowledge of core competencies (such as anatomy, physiology, and biochemistry) that is built upon foundational knowledge gained prior to medical school. Flexner identified students being admitted with inadequate background knowledge in the core competencies at the time, i.e. biology, chemistry, and physics. Flexner asserted that all medical education was built on these three cores and an inadequate grounding resulted in students struggling to grasp the knowledge in medical school, rather than thriving. Core competencies other than those three, such as writing and math skills, should reasonably be expected of medical students and medical schools should not remediate students with a lack in one or more of these additional areas. Medical schools have since increased the number of core competencies to include immunology, medicinal chemistry, pharmacology, histology, etc. Second, students must have the means to improve their ability to synthesize information to appropriately diagnose and treat patients, including interpreting data from physical examinations, laboratory tests, and imaging.

After this initial medical curricula report was published, curricular changes were made based off of Flexner's suggestions, including the development of entrance exams. Students were 
required to demonstrate a mastery of knowledge in core fields prior to gaining entrance to a medical school. After these changes were made, the medical curriculum was not reexamined until after World War II when a new document identified areas of needed change (Strassman et al., 1969). Strassman et al. (1969) pointed out that medical education needed to emphasize cellular to organismal knowledge, thus teaching students to integrate disciplines. A follow-up educational perspective on what training physicians required noted that students had been too focused on factual knowledge and rote memorization within fields, missing important connections between fields (AAMC, 1983). This perspective called for inquiry to be brought into the classroom, helping teach students to develop critical thinking skills. The perspective also highlighted impediments to curriculum change that included class size being too large, professors not having enough time with any class, and the massive increase in biomedical knowledge medical students are required to know. One method that was developed to focus medical students on developing critical thinking skills such as integrating knowledge, evaluating information, and integrating information to determine diagnoses was termed Problem Based Learning (PBL) (Barrows, 1985). Designed as a way to develop scientific and analytical reasoning skills in medical students, PBL has since disseminated to other professional fields. Since its creation, PBL has become a general term that can indicate many different types of learning assessments (Barrows, 1986). Not all of the PBL activities emphasize critical thinking, some emphasize course content and some focus on both course content and critical thinking skills. Therefore PBL is only useful for teaching students critical thinking skills if that was the intended goal. However, both students in traditional lecture based classrooms as well as PBL classrooms continue to struggle with integration, resulting in some medical educators moving to the use of concept maps to teach students the important concepts and to be able to emphasize the 
important connections between concepts (Pinto and Zeitz, 1997). The most recent review of medical education is focusing on bringing in more prepared medical students. Medical education is steering pre-medical students away from fulfilling a set number of pre-requisite courses and focusing pre-medical students on understanding fundamental science principles and competencies (AAMC, 2009). The definition of competency is repeatable use and integration of various types of knowledge (content, emotional, clinical, values, technical) daily for effective patient care (AAMC, 2009). Students are being directed toward these core competencies by medical education emphasizing integration between disciplines. The MCATs are reflective of these changes, while also requiring students to exhibit critical thinking abilities (Mededportal iCollaborative, 2014).

All of the reflections, perspectives, calls for curricular reform and commentaries on medical education (Cooke et al. 2006; AAMC, 1983; Flexner, 1910; Strassman et al. 1969) identified many different issues. Entrance exams (MCATs) were first administered in 1928 for admissions to medical schools (AAMC, 2009). With the growth of basic science and clinical research over the past century, biomedical and foundational scientific fields have undergone tremendous growth in available knowledge (Cooke et al. 2006). As the knowledge required to be an effective clinician has increased, the number of pre-requisite courses has been increased as the knowledge base has expanded. With this expanded knowledge base, both undergraduate and professional institutions have increased amounts of overall content by adding new information and updating older content. Some students are still underprepared in core competencies, while others struggle with integrating curricular content, psychomotor skills, and the attitudes required of a health care professional (Cooke et al. 2006; AAMC, 1983; Lane, 2010; O'Callaghan, 2013; Pinto and Zeitz, 1997). Where a lack of time for classroom teaching time has been identified by 
medical educators as a key issue in medical schools (AAMC, 1983), considering the increasing amount of content in medical curricula, there is not enough time to remediate students struggling with core competencies (Cooke et al. 2006; Flexner, 1910). The MCATs arecurrently being revised for 2015, increasing the scope of competencies for which it is testing and decreasing the amount of discipline-specific content, thereby focusing students on making connections between disciplines (Brouet et al., 2013), cultural diversity and awareness, communication skills, and critical thinking skills such as problem solving (Mededportal iCollaborative page, 2014). However, even with a more rigorous entrance exam focusing on some aspects of critical thinking skills, the development of critical thinking skills in medical students has not progressed as well as might have been anticipated, as noted by every medical school curricula review. Incoming students are still unprepared for certain aspects of the medical school curricula (Cooke et al. 2006), specifically being capable of applying and evaluating information. Teaching critical thinking skills is becoming even more crucial as educators expect medical students to assume the responsibility of supplementing lectures with information available outside of the classroom.

The importance of critical thinking skills has begun to be emphasized prior to medical school, as evidenced by a focus on these skills in the updated version of the MCATs. If exams drive learning, then requiring the demonstration of critical thinking skills on the entrance exam may lead to a more qualified candidate pool. Requiring students to demonstrate critical thinking on the MCAT will result in this skill becoming a priority in undergraduate education. In turn, this will decrease the amount of time medical schools have to spend training their students to develop critical thinking skills. 


\section{Shifting Focus in Veterinary Education}

Along with the medical, scientific, and technical advances of the last century, veterinary education has fallen behind the demands of society (Pew Report, 1989). The expansion of broiler chicken breeding, the use of hormones and antibiotics in livestock and livestock feed, and the development of aquaculture are just a few of the scientific and technological areas where student preparation in veterinary education has fallen behind (Pew Report, 1989). The Pew Report's call for educational reform wherein several issues were highlighted has largely gone unaddressed, and certain fields, such as veterinary training in domestic animal feed development, have continued to decline (Andrews, 2013; Marshak, 2005).

The Pew report (1989) called for a change in curriculum structure, moving away from training veterinarians as generalists. There exists too much information about the seven body systems, including the bovine, ovine, equine, feline, etc. systems, each having a distinctive physiology with which veterinarians work, to effectively train them to be proficient in everything. As North American culture has become increasingly urbanized, a need for several non-traditional types of veterinarians has been identified (Pew Report, 1989). The major areas identified in this original call for educational reform are public health, feed development and maintenance, wildlife management, and zoo veterinarian science (Pew Report, 1989). However, Marshak argues that the extreme versatility of the veterinary field is the most important aspect of animal medicine and should not be sacrificed (2005). In a recent curriculum evaluation, one of the main goals identified for graduating veterinarians is comparative animal science (Andrews $e t$ al., 2013). Additional goals in this recent evaluation (2013) emphasize core competencies to provide graduating veterinarians with professional competencies in diverse fields such as 
business, multicultural awareness, and law. One of the major themes emphasized in every goal outlined by the committee for educational emphasis was flexibility in the knowledge and training of graduating veterinarians. The 2013 curriculum evaluation's (Andrews et al., 2013) goals align with the 2005 review (Marshak), which contradicts the 1989 call for the educational reform (Pew Report) goal of specializing veterinarians early in their academic training. The 2005 review (Marshak) agrees with most of the 1989 call's goals (Pew Report), noting that the majority of changes that were called for have not been changed, but have continued to steadily decline. The feed development and maintenance veterinary field has stagnated, despite the emphasis of the Pew report (1989) on the sub-discipline (Marshak, 2005). This has resulted in a decline in the number of veterinarians capable of working with industries manufacturing bulk livestock feed (Barrington and Allen, 2010; Marshak, 2005; Pew Report, 1989). Levels of antibiotic and antimicrobial bacteria have increased due to low levels of antibiotics seeded in livestock feed (Baker, 2006). The antibiotic resistant strains of bacteria are in part responsible for zoonotic diseases that are manifesting in the human population (Murphy, 2008). This supports the Pew report's (1989) supposition that not only feed science but also public health is an important field to be incorporated into veterinary curricula.

Veterinarians are an important part of public health, where they are involved in preventing diseases from reaching the human population, both from food borne diseases as well as playing an important role in bioterrorism (Critical Needs for Research in Veterinary Science, 2005; Fosgate, 2008; Murphy, 2008; Osburne et al., 2009). Veterinarians and veterinary scientists have been responsible for the management of multiple life-threatening zoonotic diseases such as rabies, anthrax, and babeiosis (Pew Report, 1989). Veterinarians have also been responsible for developing protocols to contain and properly dispose of animal waste products 
that might cause disease (Fosgate, 2008). Veterinarians are being called upon to manage wildlife populations and control diseases, not only to preserve the animals, but also for the economies driven by wildlife tourism and hunting (Osburne et al., 2009; Pew Report, 1989). Entertainment and educational venues utilizing animals have rapidly grown over the past two decades. Veterinarians working with these venues have to be qualified to work with multiple and exotic animal species that have very distinct physiological systems and needs.

As mentioned above, there is a debate about continuing to train veterinarians as generalists or having specialized tracks during veterinary education (Eyre, 2002; Marshak, 2005; Pew Report, 1989; Radostits, 2003). All levels of science education are experiencing content overload in the classroom (Cook et al. 2006; Handelsman et al. 2007; Wood 2009). Veterinary education is no exception. Students must have a strong working knowledge of fundamental physiology because there are seven distinct types of physiology depending on animal type. Similar to medical education, the amount of information inherent to a traditional veterinary education coupled with the explosion in biomedical research in the classroom has resulted in an overwhelming volume of knowledge that needs to be learned and maintained, resulting in veterinary students being overburdened with all of this information (Cooke et al. 2006; Pew Report, 1989; Radostits, 2003). Some veterinary schools are moving away from the generalist education to an engineering model of education (Eyre, 2002; Radostits, 2003). In the engineering model of education, the first year of education is a core curriculum followed by the selection of tracks, where students specialize for their chosen career (Eyre, 2002; Radostits, 2003). This model would also allow the curricula to revive flagging tracks (such as feed programs) or create needed tracks (such as a public health track) (Pew Report, 1989; Radostits 2003). However, requiring students to specialize during professional school may result in a loss of invaluable 
flexibility that allows a veterinarian to respond to any situation (Marshak, 2005). A change in veterinary curricula is necessary, although what changes to make is unclear, as students expect to leave veterinarian school with adequate training for any given situation and professors view veterinary school as the place to learn fundamental concepts that students can then use to gain specific professional skills after their education (Hoppe and Trowald-Wigh, 2000). Both Marshak (2005) and Radostits (2003) raise excellent points that need to be considered when redesigning veterinary curricula. It is clear that the current way of training veterinarians is not adequately preparing them for the workplace, and it is not training veterinarians to fill all the roles for which they are needed in society.

The Pew Report (1989) identified four key behaviors that successfully trained veterinarians exhibit in their daily practice: thoroughness, reliability, critical thinking, and practicality. Thoroughness is necessary for any clinician since a patient's medical history must be completely examined and all lab tests must be combined with physical examination data for interpretation. Reliability is important for diagnostic purposes; symptoms should always lead to the same diagnoses and the subsequent treatment protocols and procedures must be consistently followed with precision. Critical thinking is important because a clinician must be able to take data about the patient from multiple sources (i.e., lab tests, physical examination, and medical history) and arrive at logical conclusions. Being practical is especially necessary for veterinarians because they must be able to deal with cases using the tools available to them. The 2013 curriculum evaluation (Andrews et al., 2013) devotes an entire aim to ensure veterinarians possess specific professional skills, expanding on the Pew Report's (1989) four key behaviors. These skills prepare veterinarian students for lifelong learning as well as the business acumen and financial skills necessary for owning, running, or being a member of a veterinary practice. 
These skills, such as leadership and evaluative thinking, have been identified as an incredibly important part of the education for veterinarians currently in professional school (Harris and Lloyd, 2011; Henry and Treanor, 2010; Lloyd, 2007)

Critical thinking skills are a set of skills that every profession wants to cultivate in their students. However, critical thinking skills are a very difficult skillset to train and assess. With lectures emphasizing didactic information, critical thinking is not always highlighted to the degree educators would prefer (Michel et al. 2009; Wood, 2009). In veterinary curricula, the overwhelming amount of content in lectures limits students to memorizing information (Pew Report, 1989). This may prepare a student for taking course exams, but does not impart any lasting gains in learning (Michel et al. 2009). In addition to limiting critical thinking, the magnitude of coursework required for veterinary school leaves very little time for psychomotor skill development (Pew report, 1989). Veterinary school professors have identified veterinary school as the place to learn fundamental concepts, and believe that the students should learn job skills after they leave (Hoppe and Trowald-Wigh, 2000). Currently in veterinary curricula, the first three years consist largely of intensive lectures with associated labs, including a significant lecture component. This leaves the final year for development of psychomotor skills which is not enough to develop the necessary skill set and experience (Pew Report, 1989). Although discussion has taken place on how to change the curricula, very little has actually been put into place (Eyre, 2002). Students need to possess critical thinking skills to be successful in the veterinary curricula from the beginning. This shifts the focus to improving the pool of candidates applying to veterinary school. 
Shifting Focus in Undergraduate Science Education

Similar to concerns in professional schools, concerns about undergraduate science education have stemmed from the rapid gains of knowledge from biomedical and fundamental scientific research (Cooke et al. 2006, Radostits 2003, Knight and Wood 2005; Wood, 2009). An increasing volume of facts, concepts, and terminology are being added to courses without anything being removed (Cooke et al. 2006; Zheng et al. 2008). Educators attempt to cover an overwhelming volume of content in classrooms and neglect training students in understanding problem solving and critical thinking (Tanner and Allen, 2004). Although necessary for students to understand the breadth of a course, teaching large volumes of content does not always teach students critical thinking skills that are necessary for graduate and professional programs/jobs where they are required to apply their knowledge in novel ways (Kogan and McConnell, 2001; Knight and Wood, 2005; Zheng et al. 2008). Educational reform has been initiated in the science, technology, engineering, and math (STEM) fields (Handelsman et al., 2007). Both the National Research Council and the National Science Foundation put out calls for changing/updating undergraduate science education, providing money for both institutions and individuals interested in educational research using altered teaching styles and/or technology in the classroom (Wood and Handelsman, 2004). An area of focus within the science education reforms is cutting back on content taught, and focusing students on concepts that can be applied to various disciplines or situations (AAAS, 2011). A major change arising from these calls for reform was the development and implementation of the National Academies Summer Institutes on Undergraduate Education in Biology to train educators (Wood and Handelsman, 2004). These summer Institutes are intensive week long courses where faculty and staff are trained to approach 
education using the scientific method (Wood and Handelsman, 2004). This has become known as scientific education (Handelsman et al., 2007).

Scientific education uses the principle of backward design, where the overarching goals of the course are first determined (Handelsman et al., 2007). This is different from traditional course design, where content from textbooks drives lectures and exams, and course goals are often neglected. Once determined, the goals are then broken down into more approachable pieces, known as learning objectives (Handelsman et al., 2007). These learning objectives can be directly converted into test questions or assignments, and drive where assessments (quizzes, papers, exams, projects, etc.) focus student learning (Cooke et al., 2006; Handelsman et al., 2007; Wood, 2009). Defining course goals and learning objectives provides a way for educators to structure their course assessments towards the knowledge and concepts they deem to be critically important (Handelsman et al. 2007; Lodish and Rodriguez, 2004; Wood, 2009).

Clearly stated course goals and learning objectives allow educators to tailor their course and curriculum to ensure students are learning the fundamental concepts of the class (Handelsman et al., 2007; Lodish and Rodriguez, 2004; Wood, 2009), as well as covering the required content of the course. Defining critical thinking skills as a course goal allows instructor to create assessments that require students to demonstrate problem solving abilities (Handelsman et al., 2007). If critical thinking skills are not an explicit focus of the course, they may be neglected in favor of overwhelming amounts of course content (Bloom et al., 1956; Krathwohl et al,. 1964; Krathwohl, 2002; Wood, 2009). By focusing on critical thinking skills as assessable course goals, educators can build activities that enable students to use content as a platform to think through situations designed to challenge them (Felder and Brent, 1996; Knight and Wood, 2005; Lodish and Rodriguez, 2004). Shifting time reserved for lecture to problem solving activities 
transforms the traditional, passive classroom into an active classroom (Allen and Tanner, 2005; Felder and Brent, 1996; Knight and Wood, 2005; Michel et al., 2009; Wood, 2009). This shift is often daunting for the instructor, and educators experience a perceived loss of control (Felder and Brent, 1996). The active classroom does not imply that an educator stops shaping the direction of the class; activities can be designed ahead of time or on the spot, controlled, and guided by the educator (Felder and Brent, 1996).

Many problems educators experience with active learning are due to a mismatch between what they perceive is happening, both as an instructor and a curriculum developer, and the reality of what is actually occurring (Felder and Brent, 1996; Wood, 2009). Active learning is a tool the educator can use to evaluate the effectiveness of activities, teaching interventions, and lectures (Baskas, 2012; Wood and Handelsman, 2004). Fostering an active classroom facilitates a learning environment in which the students are capable of grappling and struggling with concepts so that they can move past passive listening (Michel et al., 1999). In an active classroom, students are engaged in activities, thinking through problems, and receiving feedback while they are participating in an activity (Michel et al., 1999, Bonwell and Eison, 1991; Felder and Brent, 1996). These activities should move students from merely recalling classroom information to integrating that information in novel ways and scenarios (Bonwell and Eison, 1991). Either phase of conceptual learning may be engaged, depending the individual student's understanding of the material being covered. A commonly used example of this is case studies, where students are taught the knowledge and then given a scenario or patient information where a diagnosis is required. Students have to synthesize knowledge from the classroom, often from multiple units within the class, to solve different aspects of the case study. 
Traditional classrooms are defined as predominately lecture driven, with little if any student input (Handelsman et al., 2007; Michel et al., 2009). Traditional classroom approaches to assessment consist of a small number of exams that consist of a few types of exam questions: multiple choice, matching, or true and false (Michel et al., 2009). Traditional classrooms are an excellent way to disseminate large volumes of information, but students are often not engaged and do not retain a lot of the information (Michel et al., 2009; Wood, 2009). Therefore, learning in traditional classrooms is often called passive learning because the students do not participate in learning, but merely observe lectures (Michel et al., 2009). Educational reform has begun to move away from the traditional classroom paradigm in order to eliminate/reduce content overload (Cook et al., 2006; Michel et al., 2009; Radostits, 2008; Zheng et al. 2008)

Active learning is an evolution of traditional teaching (Allen and Tanner, 2005; Michel et al. 1999; Wood, 2009) and was designed to engage students by asking them to use the information they have learned (Michel et al., 1999, Bonwell and Eison, 1991; Felder and Brent, 1996). Conclusions based on research examining whether active learning is more effective than passive learning are mixed (Michel et al. 1999; Schwerdt and Wupperman, 2009). Specific questions about different aspects of active learning can be more difficult to assess, with some variables being uncontrollable/unquantifiable (Michel et al. 1999; Schwerdt and Wupperman, 2009). Students exhibit varying responses to active learning that range from hostility to enthusiastically embracing the new techniques (Felder and Brent, 1996). Hostile students will often complain in teaching evaluations that they are paying to be taught, not to teach themselves (Felder and Brent, 1996). Many educators (especially those who have additional research or clinical duties) do not want to spend their valuable time to alter pre-existing courses, are concerned about student evaluations, or are concerned they will not be able to cover all of the desired material (Knight 
and Wood, 2005; Wood and Handelsman, 2004). Active learning results in reduced availability of class time for the dissemination of information to the students, but if framed appropriately, it makes students more accountable for the material covered in the classroom (Felder and Brent, 1996). If activities are designed so that students must read/study information prior to coming to the classroom, the classroom becomes a place where the instructor can watch the students use their newly gained knowledge and catch any misconceptions immediately (Felder and Brent, Handelsman et al., 2007; Tanner and Allen, 2005; Wood, 2009). In larger classes, educators will often enlist the aid of additional instructors or teaching assistants; another commonly used technique is to break students up into peer groups, and the instructor can move between groups and silently observe how the students are functioning. Group work can often be used for peer feedback and evaluation, with the instructor choosing to step in and clarify questions when the entire group is struggling.

Assessment tools vary greatly, so scientific educators are compiling different forms into discreet books or websites for easy access (Angelo and Cross, 1993). They are traditionally broken into two types, summative and formative (Wood, 2009). Summative assessments, such as a test, are used in traditional classrooms (Handelsman et al. 2007; Wood, 2009). These occur at the end of a discrete unit of information, such as a unit in a textbook. The assessment sums the information covered by the section/unit, but does not provide feedback on any misconceptions the student may have formed until after the testing is complete (Handelsman et al. 2007; Wood, 2009). In contrast to summative assessments, formative assessments are administered often and while students are learning the material (Handelsman et al. 2007; Tanner and Allen, 2005; Wood, 2009). These are designed to provide feedback for both the student and the educator about the knowledge a student is learning during the actual learning process (Tanner and Allen, 
2005; Wood, 2009). This allows both the students and educators to identify misconceptions as they arise (Lodish and Rodriguez, 2004; Tanner and Allen, 2005; Wood, 2009). With this, the educator can elect to alter the rest of the class period or address the misconception in some other way (Allen and Tanner, 2005).

Assessments can be classified by the type of thought processes students must use to successfully complete the activity (Handelsman et al. 2007; Wood, 2009). This is accomplished using a taxonomy developed to effectively communicate about vaguely defined educational terms such as 'learning' and 'thinking' (Bloom et al., 1956). This taxonomy was further used to define outcomes of learning assessments (Krathwohl et al., 1964). Bloom's Taxonomy of Cognitive Processes suggests learning follows certain steps with each step building upon the previous steps (Pungente and Badger, 2003). The six levels of Bloom's taxonomy are 1 knowledge, 2 - comprehension, 3 - application, 4 - analysis, 5 - synthesis, and 6 - evaluation (Bloom et al. 1956; Krathwohl et al. 1964). The six levels of Bloom's Taxonomy can be broadly grouped into three orders of learning (Handelsman et al., 2007). Knowledge and Comprehension are considered lower order, where students are only challenged to parrot information in the same structure as it was taught (Crowe et al. 2008). Application is sometimes considered lower order, but is often grouped with Analysis as a mid-level order of learning, where students are required to apply knowledge to a novel situation (Crowe et al. 2008). Evaluation and Synthesis are higher order, as students use prior knowledge to observe, analyze, and evaluate problems with a different content base (Crowe et al. 2008). The higher order skills are not considered hierarchical, and may be alternatively arranged by personal preference (Krathwohl, 2002). Bloom's taxonomy is used to create quality assessments that vary in type and 
can be used as a powerful tool to ensure course goals are being met, and allows educators to define critical thinking as a course goal.

\section{Thesis Objectives}

Physiology is a fundamental requirement for both medical and veterinary curricula (Flexner, 1910; Pew Report, 1989). It is also a discipline that is taught to both science and nonscience majors in undergraduate institutions (Escribano et al., 2011; Feder, 2005; Wilke, 2003). The field of physiology is a study of integrated processes, similar to learning (Escribano et al., 2011; Feder, 2005). Because the AAMC is focusing on competencies instead of pre-requisites for medical school (AAMC, 2009), physiology classrooms have the capability to become an excellent place for learning fundamental competencies such as integration, evaluation and critical thinking. The revised MCATs for 2015 will emphasize on connections between disciplines (Mededportal iCollaborative, 2014). The capacity to integrate information into concepts is something with which medical students are struggling. Medical educators are using concept maps as an attempt to illustrate important connections for medical students to facilitate integration of disciplines (Pinto and Zeitz, 1997). The focus on integration and competencies that span scientific disciplines also focuses on critical thinking skills such as evaluation and synthesis. Physiology, because it is a study of processes, can be used to teach these critical thinking skills in undergraduate institutions before students apply to professional schools. This discipline naturally falls higher on Bloom's taxonomy because students are required to apply information to integrative systems for assessments. Since physiology is a study of interactive processes, it can also be used as a tool to teach students concepts and thought processes that can be applied to other areas of study (Feder, 2005). Laws of chemistry and physics are often discussed and worked through in a physiology course, bringing a very important element of 
integration into the classroom. Comparative physiology can also be used to highlight why humans cannot live in the same environments as animals, and explain why humans live in or maintain artificial environments. Assuming students will notice the integration of these fields often leads to a mismatch in learning goals, where an instructor will believe that they taught the students about integrative thinking because it was used in the class. Students will not always pick up on a concept or connection that is not specifically emphasized by the instructor. Therefore, if physiology is taught with a specific emphasis on basic concepts and the integration between fields, the discipline lends itself quite well to the learning process. Teaching physiology to a broad scope of undergraduates will not only better prepare students planning on careers as health professionals, but teach invaluable critical thinking skills to students going into other career paths.

\section{Objective 1}

Using conceptual knowledge of pulmonary physiology (comparing similarity of structure and function) for evaluative purposes has been shown to be a different thought process than the knowledge of pulmonary physiology that is tested for on exams (McGaghie et al. 2000). The first objective of this thesis is to examine how introducing physiology concepts into an upper classmen, non-physiology science course to stimulate the assimilation phase of conceptual learning affects the students' ability to answer exam questions written by professionals in the medical, veterinary, and pharmacy fields. This objective examines students' abilities to create connections between basic concepts of physiology (that can be explained using physics or chemical laws) to word problems describing situations that might occur in health professions (requiring conceptual knowledge of physiology to answer the questions, but is not specifically asked for in the questions). 


\section{Objective 2}

Because self-evaluation is such an important component of critical thinking skills in disciplines such as physiology, online activities and other multimedia files can be used to stimulate this self-awareness. Integrating computer systems in the classroom has occurred and many courses provide segments, or entire sections of classes, online. These online parts of a class can be used as minimally as providing students with electronic access to Powerpoint files of lecture material or as extensively as providing students with interactive games. This provides a place where students can take responsibility for the pace of their learning, and control how much material they cover (Gaytan and Pasaro, 2009). Providing multimedia files can enhance material covered in lecture, and provide additional resources for students struggling with concepts from class (Gough, 2011). The second objective of this thesis is to examine what effect providing additional multimedia files during a physiology course have on student outcomes (i.e. how does file access correlate with exam grade). 
Chapter II:

Methodological Approaches 


\section{Objective 1}

\section{Educational Intervention}

Students were allotted four 50 minute class periods at the end of the semester in an Invertebrate Zoology class for a pre- and post-test, lectures, and classroom activity time. Lectures focused on basic concepts in respiratory and cardiovascular physiology, such as gas diffusion and exchange within the body. These topics were selected because students were learning similar concepts during the normal class period. Each intervention lecture lasted approximately 15-20 minutes, followed by a period of questions with the instructor in which students were asked to apply the knowledge from the lecture in activities. Each series of questions in lecture were designed to culminate in the diagnosis of a patient with symptoms.

\section{Class Setup}

The educational intervention occurred during an upper level undergraduate biology elective, Invertebrate Zoology. The course was a combination of short, traditional didactic lectures and active learning exercises that met three times a week for an hour each time. During the course, students were given time in class to work on a taxonomic key. This was indirectly used as an assessment, since students were required to use it during the final exam and would not be capable of passing the final without the key. Students worked on the taxonomic key in groups of 3-4, and group members assessed their partners for a small percentage of the overall student grade. Students received a handout detailing construction of a taxonomic key, including how to construct appropriate questions to distinguish between organisms of different phyla, class, and orders. Other assessments that contributed to the overall grade included a lab component, three unit exams, four group assessments, and a term paper. For all of these assessments, students were 
provided with handouts and verbal instructions, and the instructor/TA was present to provide feedback and assist students.

\section{Class Demographics}

There were 23 students registered for the Invertebrate Zoology course. Of the 23

students, 21 completed the pre- and post-test, as well as the student perception questionnaire. Because of the listed requirements for Invertebrate Zoology, students had to be upper classmen to enroll for the course. The students were a mixture of juniors and seniors. The average age of students enrolled in the course was 21 (age ranged from 19 to 28). Of the 21 students that participated in the educational intervention, 10 identified as having taking at least one physiology course during their undergraduate studies. This physiology course had to either have been taken prior to the class or students had to be concurrently enrolled in a physiology class with Invertebrate Zoology. Students reported future career interests early in the class, and they ranged from industry, education, veterinarians, to various types of medical doctors.

\section{Assessments}

To assess the outcomes of the educational intervention, students were given a pre- and a post-test, a pre- and post-questionnaire, and an open-ended question during the final examination asking for an explanation of how information from the class had been used outside of the classroom. The pre- and post-test was administered in class by the TA, without the instructor being present. The pre- and post-questionnaire was administered online using a website, surveymonkey.com. Data from the tests and the questionnaires were used to quantify student learning gains, student perceptions of their learning, and examine the association between perception and performance. 
Pre- and post-test

The pre- and post-test was designed to assess the effectiveness of the educational intervention. A pharmacist (licensed in 2000) and veterinarian (licensed in 2009), actively practicing in their fields, graciously designed questions similar to what they had seen during their graduate or professional schooling. A medical school professor provided questions similar to those posed on first year medical exams. The three professionals were given instructions to attempt to lower the difficulty of the questions to where they would be appropriate for upper level classmen at a typical 4-year university. Based on the content covered in the class, Invertebrate Zoology, they were asked to focus their questions on concepts from respiratory and cardiovascular physiology. Prior to writing their questions, the professionals requested a brief list of the topics covered in Invertebrate Zoology. The professionals were asked to write three to five multiple-choice questions.

After the questions were designed, the professionals were asked to send their questions to the TA in the course. The same test questions were used in both the pre- and the post-test so that improvements in student performance could be quantified. The total number of questions from all three professionals (12) was used to determine the length of time students were given to complete the exam, 30 minutes for both exams. This length of time was determined appropriate to allow students ample time to think through each question and still allow time after the pre-test and before the post-test to maximize time spent on the educational intervention. To avoid teaching to the exam, the instructor was blinded to the content of the pre- and post-test.

\section{Pre and post questionnaire}

On the days students were given the pre- or post-test, they were also emailed a link from surveymonkey.com to complete an online questionnaire. Two of these questions were written by 
the medical school professor and one was written by the course instructor. In the pre-quiz, students were asked to rank their confidence at answering each of the three questions (questions from both the medical school professor and the course instructor were used for the quiz) using a Likert scale from 1-10. The post-quiz included the same questions as the pre-quiz whereby students were asked to rank their confidence, as well as standard demographic questions such as age, gender, race and a few identifying questions about the career toward which the student was focusing, and if they had taken any previous physiology courses.

\section{Quantitative Analyses}

Data from the pre- and post- test were compared and the difference between the two identical exams was quantified as learning gains, using the equation:

$$
\text { Normalized learning gains }=[(\text { post test score }- \text { pre test score }) /(\text { total number of questions }- \text { pre test score })] * 100
$$

from Knight and Wood (2005). Learning gains were assessed in two separate ways, by question and by student. Differences from pre- and post-quiz confidence rankings were collected and associated with learning gains to identify if student self-perception affected student performance. Performance was also associated with student identification of career goals, to assess if students preparing for different careers performed differently.

\section{Statistical Analyses}

All quantitative analyses were done using JMP software. Prior to any statistical tests, data were assessed for normality using the Shapiro-Wilk test. Both differences in learning gains by question type (medical, veterinary, and pharmacy) and differences in learning gains by student career goal (dental, medical, veterinary, or other) were determined using a one-way ANOVA. Data were presented as means \pm SEM. Data from the pre- and post- quiz were combined to create a single score that was defined as student perception. The post-quiz also included a few basic demographic questions such as gender and age. The effect of student perception on student 
performance was assessed by associating student perception with student differences between pre and post-test score. Overall student confidence was summed into one number and associated with learning gains.

\section{Objective 2}

\section{Class Demographics}

During the course of the semester in the mid-level physiology course, students had multiple instructors and access to an online site designed for the course. All instructors used the site to post lecture files, study guides and practice questions. One of the course instructors provided additional content information as various types of multimedia files through the online site. These files included audio files that the instructor designed to focus on a single concept, animation clips taken from the internet to illustrate points, content summary files that focused on pulling all of the information together for a specific concept, as well as lecture files and practice exam questions.

\section{Data Processing}

Every computer click was registered by user ID automatically by the course website, SOLE. This data set was collected from the IT department after the end of the semester. Data were sorted by parent ID to identify what each click was accessing. All clicks representing access that did not have a parent ID, were replicates, or were accessing folders (instead of files) were deleted from the data set. Data were then separated by type of file accessed into units. Units for the instructor providing the multimedia files could then be processed for data analysis. Within each unit, the data were sorted by user ID. Because students would often double click on files, an audio or video file was considered accessed more than once if there was at least 2 minutes difference between timestamps of access. For lecture files and other word or .pdf files, 
there was a 10 minute threshold to count it as an additional access. The total time files were accessed could not be accurately quantified because there was no way to determine if students were actively studying, if multiple tabs were opened on their browsers, or if they had walked away from their computers. The number of times file types were accessed was tallied by student user ID for each unit exam, and then combined across all four units where the files were provided.

Statistical Analyses

Student exam scores were correlated with number of times each file type was accessed using a spearman-rho ranked correlation test. 
Chapter III:

Results 


\section{Objective 1}

\section{Learning Gains}

Differences in performance between question type (medical, veterinarian, and pharmacy) were quantified using learning gains (Knight and Wood, 2005). Learning gains from the pre- and post-test were calculated by question type (medical, veterinarian, and pharmacy; Table 1). Regardless of question category, there were positive learning gains (Table 1). Differences between question categories are shown in Table 1. There was no significant differences between the three groups $(\mathrm{p}>0.05)$.

Table 1. Summary of Averages and Standard Errors for Learning Gain Question Categories. A summary of descriptive statistics for learning gains calculations by question category. Learning gains were calculated using the equation: Normalized learning gains $=[($ post test score - pre test score)/(total number of questions - pre test score)]*100, from Wood and Knight (2005). Although there is an overall positive increase in learning gains, there is no significant difference $(\mathrm{p}>0.05)$ between question categories. Gain indicates the percent increase of performance between the pre-test and post-test for a category of questions across the entire class.

\begin{tabular}{|l|l|l|}
\hline Question Type & Mean & Standard Error \\
\hline Medical Questions & $+15 \%$ & $\pm 7.3 \%$ \\
\hline Pharmacy Questions & $+06 \%$ & $\pm 6.8 \%$ \\
\hline Veterinarian Questions & $+06 \%$ & $\pm 17 \%$ \\
\hline
\end{tabular}

To identify if a student's projected career path influenced their response to the educational intervention, performance was assessed using learning gains, but categorized by career goals. Learning gains for every question on the pre-/post-exam was summed to generate an overall learning gain score for the educational intervention on a per-student basis. Learning gains were positive regardless of identified career path (Table 2). No differences in performances by career type were observed, as assessed using a one-way ANOVA (Table 2). 
Table 2. A summary of descriptive statistics for learning gains calculations by student. Students are grouped together based on their self-identified career paths. The other category includes pre-veterinarian students, biology education students, a botanist researcher, and students interested in various aspects of industry. Normalized learning gains $=[$ (post test score - pre test

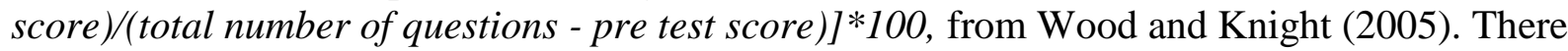
was an overall increase in learning gains but a one-way ANOVA showed no significant difference between career types ( $p>0.05$ ). Gain indicates the mean percent increase of performance between the pre-test and post-test for a category of questions by individual students.

\begin{tabular}{|l|l|l|}
\hline Projected Career Path & Mean & Standard Error \\
\hline Medical & +19.62 & \pm 6.15 \\
\hline Veterinary & +16.50 & \pm 16.50 \\
\hline Dental & +12.29 & \pm 7.53 \\
\hline Other & +7.88 & \pm 5.69 \\
\hline
\end{tabular}

Student Perception

To assess if student self-perception of their abilities was affecting their performance, students were given a pre-/post-intervention questionnaire where they were asked to rank their abilities to answer physiology questions. The overall class confidence increased significantly $(\mathrm{p}<0.05)$ following the educational intervention, where the mean represents the difference between the pre- and post- questionnaire scoring by individual student averaged across the entire class ( $\mathrm{M}_{\text {conf.: }}:+6.2, \mathrm{SE}_{\text {conf: }} \pm 1.22$ ). To quantify the effects of student self-perception on their performance, differences between the pre-/post-intervention questionaire were associated with overall student learning gains. There was no association of student confidence with the changes in learning gains $\left(\mathrm{R}^{2}: 0.0032\right)$ (Figure 1$)$. 


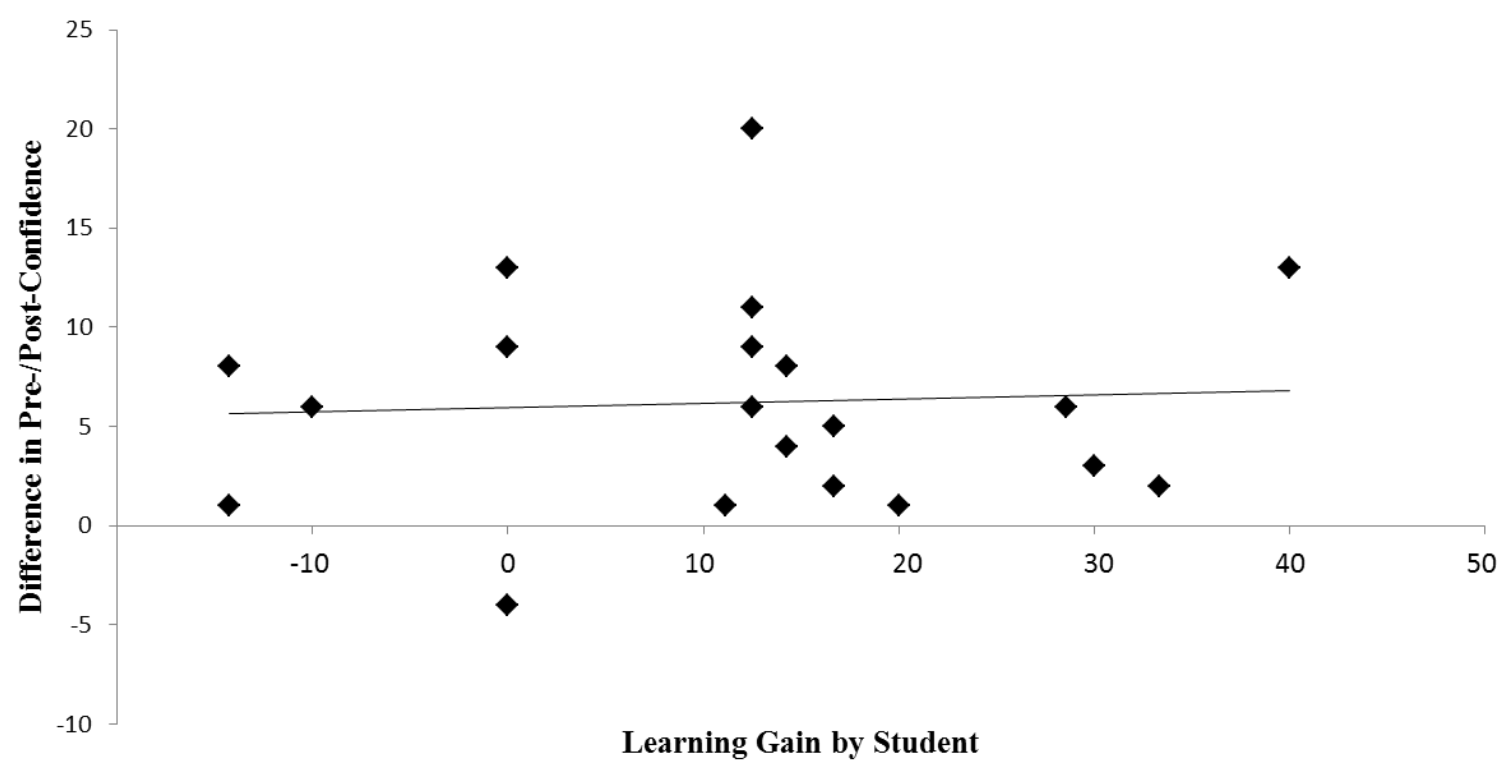

Figure 1. Association of learning gains with the change in student self-confidence. Students were given a pre-/post-intervention questionnaire to assess their confidence. The change in that measure from pre-test to post-test was associated with learning gains. There is no significant association of student confidence with learning gains $\left(\mathrm{R}^{2}: 0.0032\right)$.

\section{Objective 2}

\section{Overall File Access}

The sum of all file types across all four units was summed together and correlated with the average of the four unit exams. There is a significant positive correlation between the number of times all files were accessed and the average of the exam scores ( $\rho: 0.22, \mathrm{p}: 0.01)$ (Figure 2).

\section{Audio}

Audio files were available for all four units and showed a significant correlation with average of the four exam scores ( $\rho: 0.21, \mathrm{p}: 0.014)$. Number of times audio files were accessed showed a significant correlation for all four exams $\left(\rho_{\text {exam1 }}: 0.28\right.$, pexam $1_{0}: 0.0009 ;{ }_{\rho e x a m 2}: 0.2$, pe $_{\text {xam2 }}: 0.026$; $\rho_{\text {exam3 }}: 0.2$, pexam3 $\left._{0.022 ;} \rho_{\text {exam4 }}: 0.25, p_{\text {exam4}}: 0.005\right)$ (Figure 3 ). 


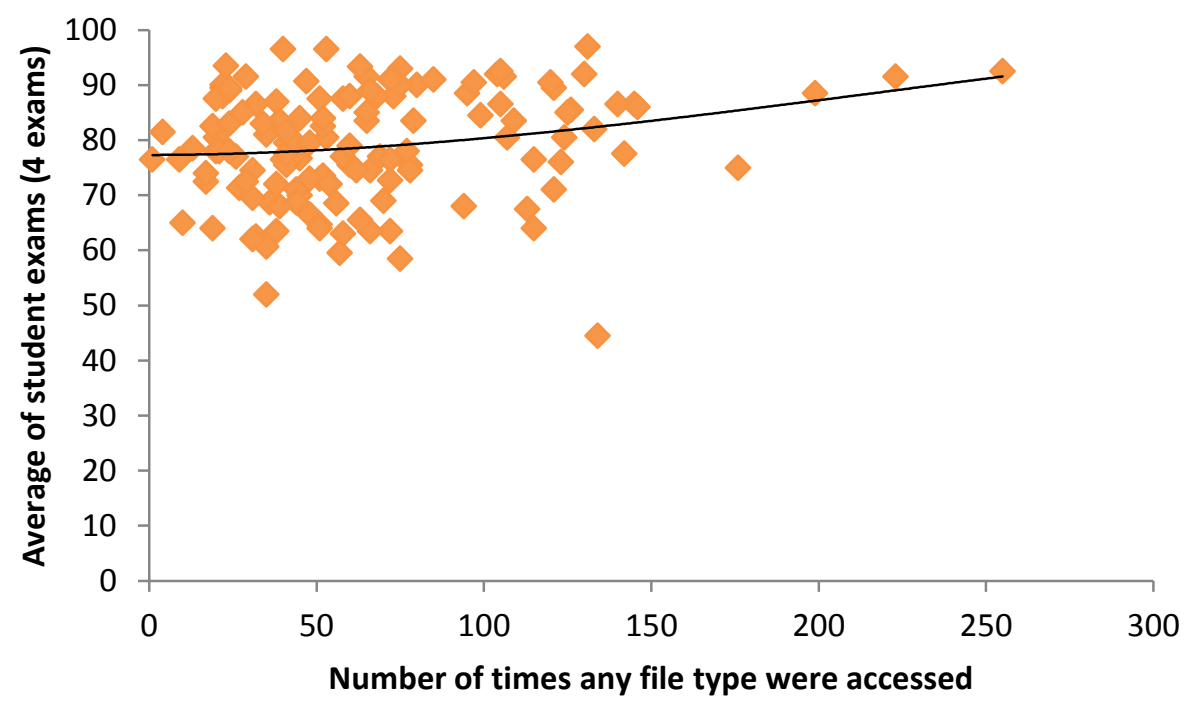

Figure 2. Correlation of Number of Times Summed Files from Course Website were Accessed with the Average of Student Exam Scores. There was a significant correlation of the number of times the sum of all files were accessed from the course website and the average of all four unit exams ( $\rho: 0.22, p: 0.01)$. Correlations were determined using a non-parametric spearman-rho's ranked correlation test. Best fit lines were done using a fourth order polynomial $\left(\mathrm{R}^{2}: 0.0489\right)$.

Video

Video files were only provided during three of the four units. Overall, number of times video files were accessed did not significantly affect the average of the exam scores ( $>0.05)$

(Figure 4). However, number of times video files were accessed for the first unit did show a significant effect on exam 1 scores ( $\rho: 0.29, p: 0.0007)$. Number of times video files were accessed for the other two units did not show a significant correlation with exam scores ( $p>0.05$ ). 

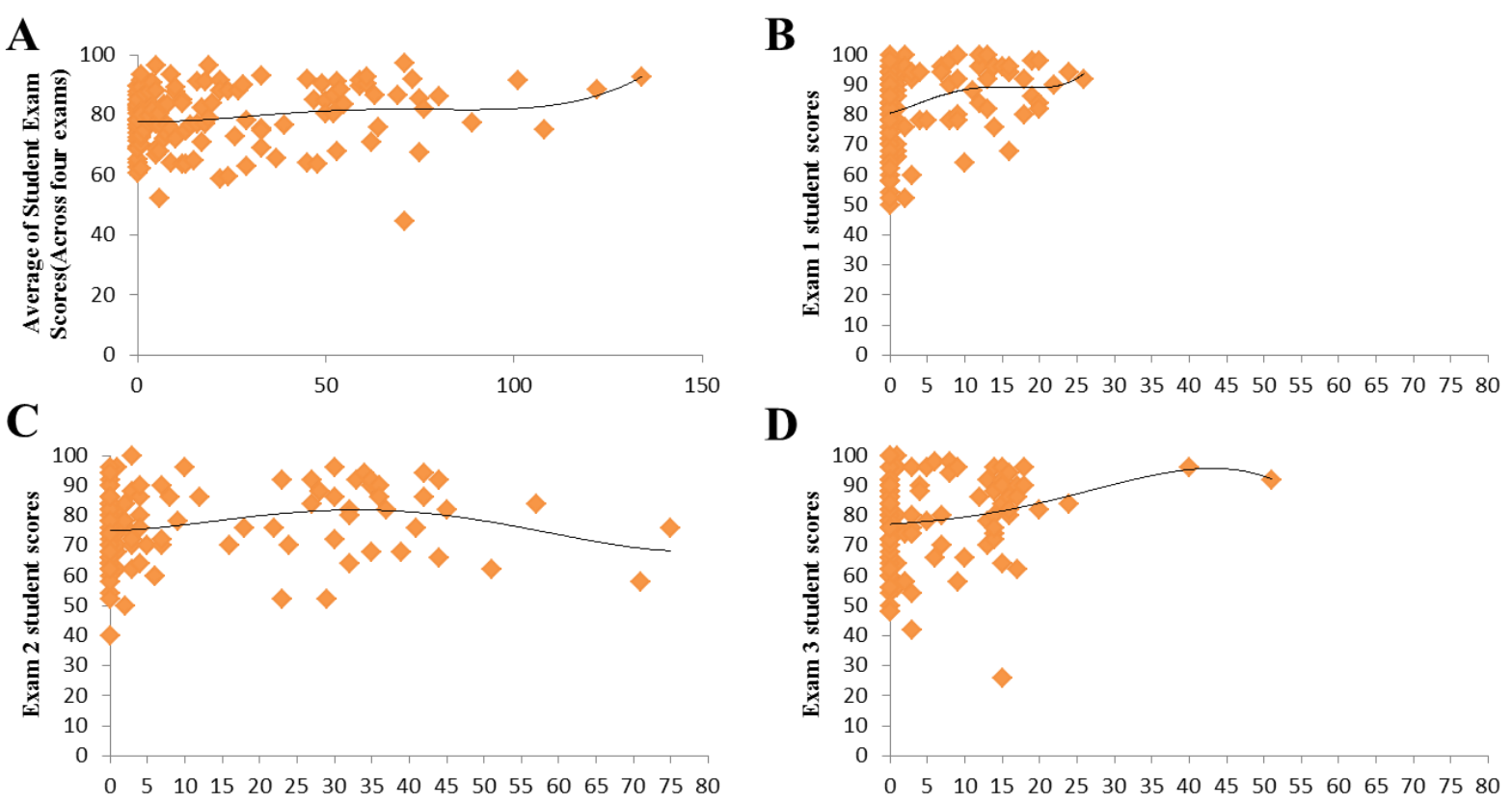

D
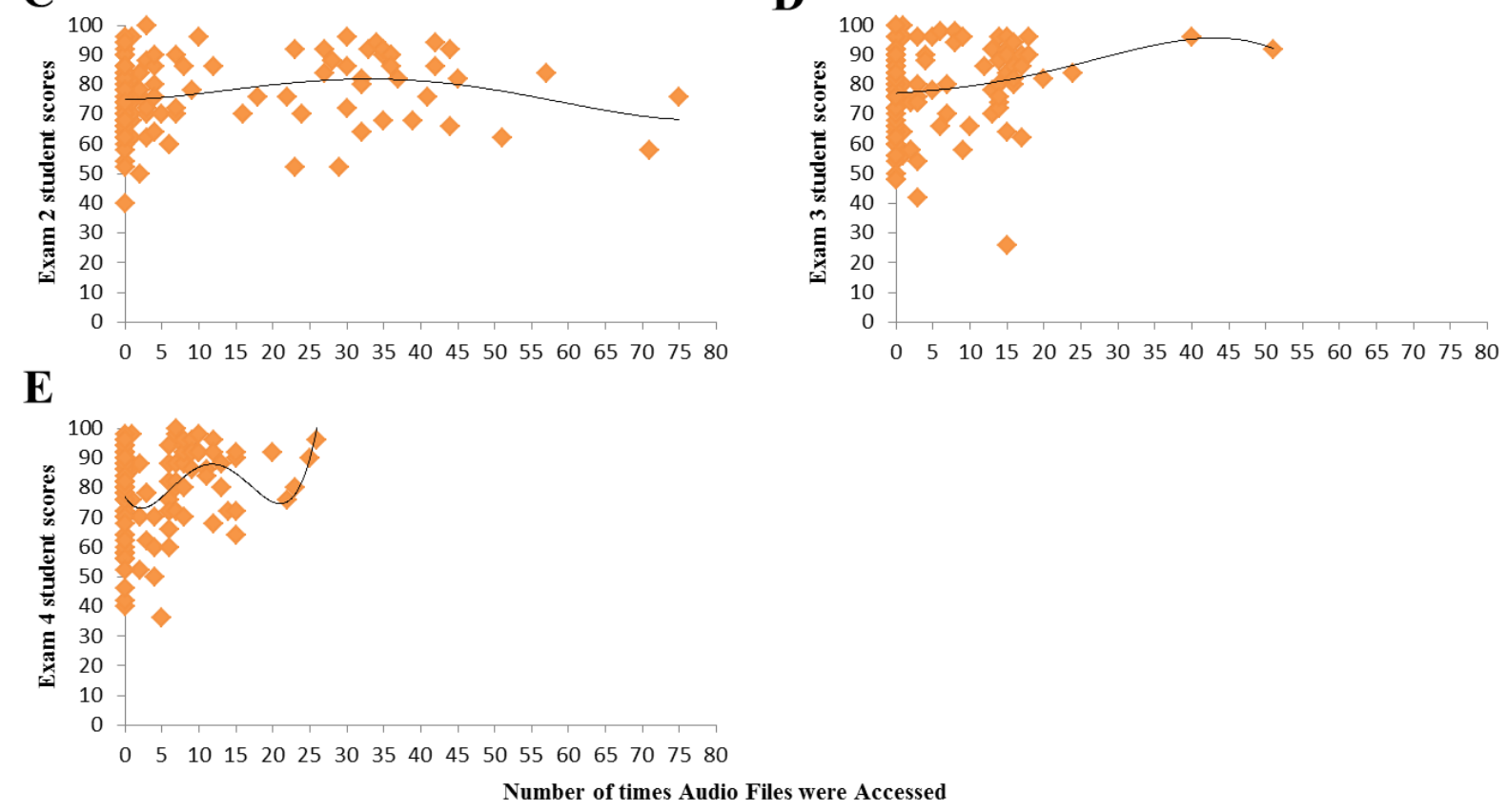

Figure 3. Correlation of the number of times audio files were accessed with student exam scores. There was a significant correlation of the number of times audio files were accessed, both overall across all four units where they were available $(A: \rho: 0.21, p: 0.014)$ and on each unit exam (B: $\rho_{\text {exam } 1}: 0.28, p_{\text {exam } 1}: 0.0009 ; C: \rho_{\text {exam2 }}: 0.2$, pe $e_{\text {xam } 2}: 0.026$; D: $\rho_{\text {exam } 3}: 0.2, p_{\text {exam3 }}$ : $\left.0.022 ; \rho_{\text {exam } 4}: 0.25, \mathrm{E}: \mathrm{p}_{\text {exam } 4}: 0.005\right)$. Correlations were determined using a non-parametric spearman-rho's ranked correlation test. Best fit lines were done using a fifth order polynomial $\left(\mathrm{R}_{\text {totalexams: }}^{2}: 0.04 ; \mathrm{R}_{\text {exam } 1}^{2}: 0.09 ; \mathrm{R}_{\text {exam } 2}^{2}: 0.06 ; \mathrm{R}_{\text {exam } 3}^{2}: 0.04 ; \mathrm{R}_{\text {exam } 4}^{2}: 0.10\right)$. 

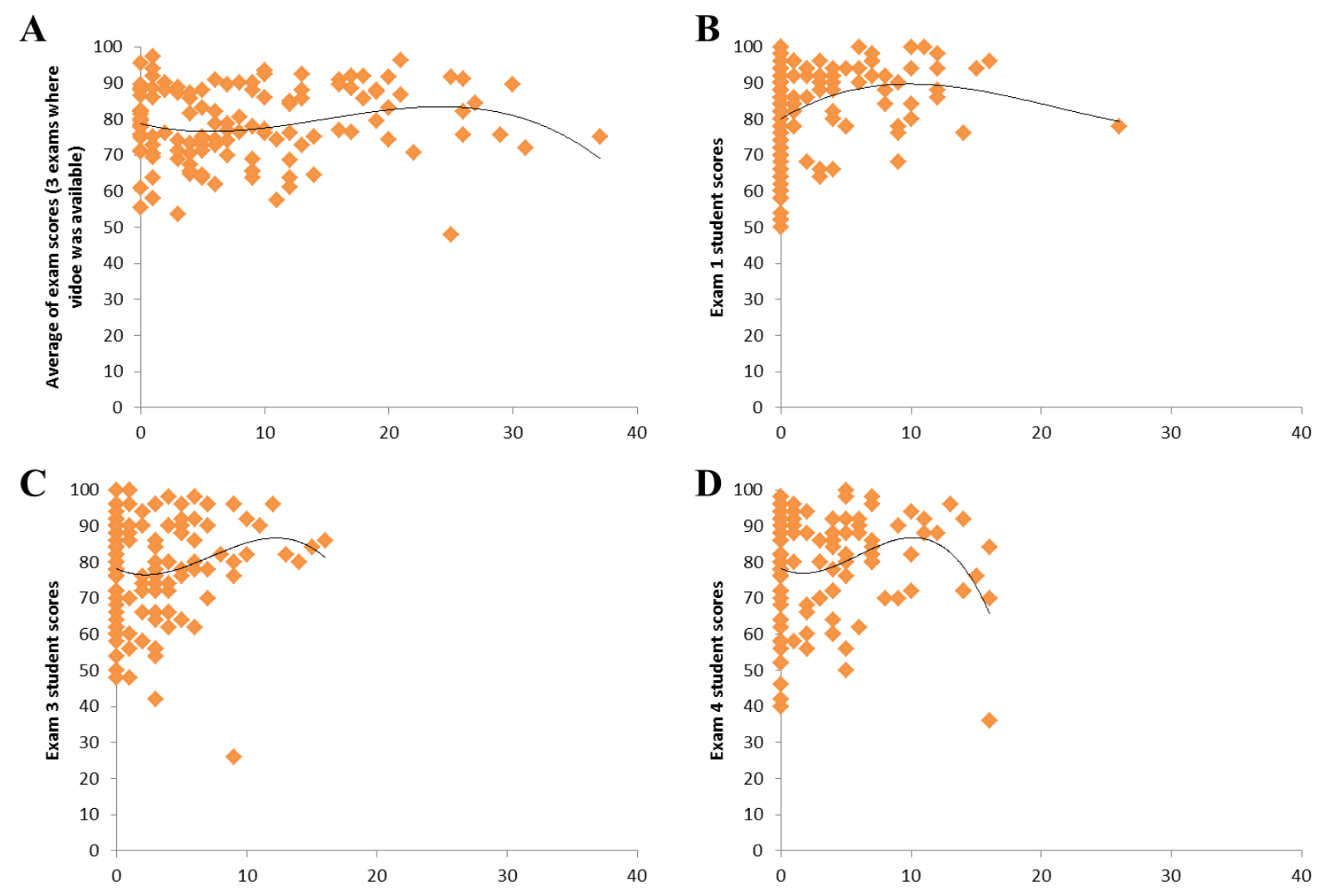

Number of Times Video Files were Accessed

Figure 4. Correlation of the number of times video files were accessed with student exam scores. Access to video files did not significantly correlated with the average of the overall unit exams where video files were available (3 units). Only one unit (Exam 1) (B) showed a significant correlation between video file access and student exam scores ( $\rho: 0.29, \mathrm{p}: 0.0007)$. Correlations were determined using a non-parametric spearman-rho's ranked correlation test. Best fit lines were fit using a fourth order polynomial $\left(R_{\text {totalexams: }}^{2} 0.05 ; R_{\text {exam } 1}^{2}: 0.10\right.$;

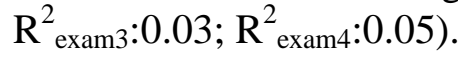

\section{Practice questions}

Practice questions were available for all four units, but there was no significant correlation between overall access to the number of times practice questions were accessed and the average of the four exams ( $>0.05)$ (Figure 5A). There was a significant correlation between exam 1 scores and the number of times practice questions were accessed ( $\rho: 0.21, p: 0.01)$. The 
other three exams did not show a significant correlation between practice question accession number and exam scores ( $\mathrm{p}>0.05)$ (Figure 5).
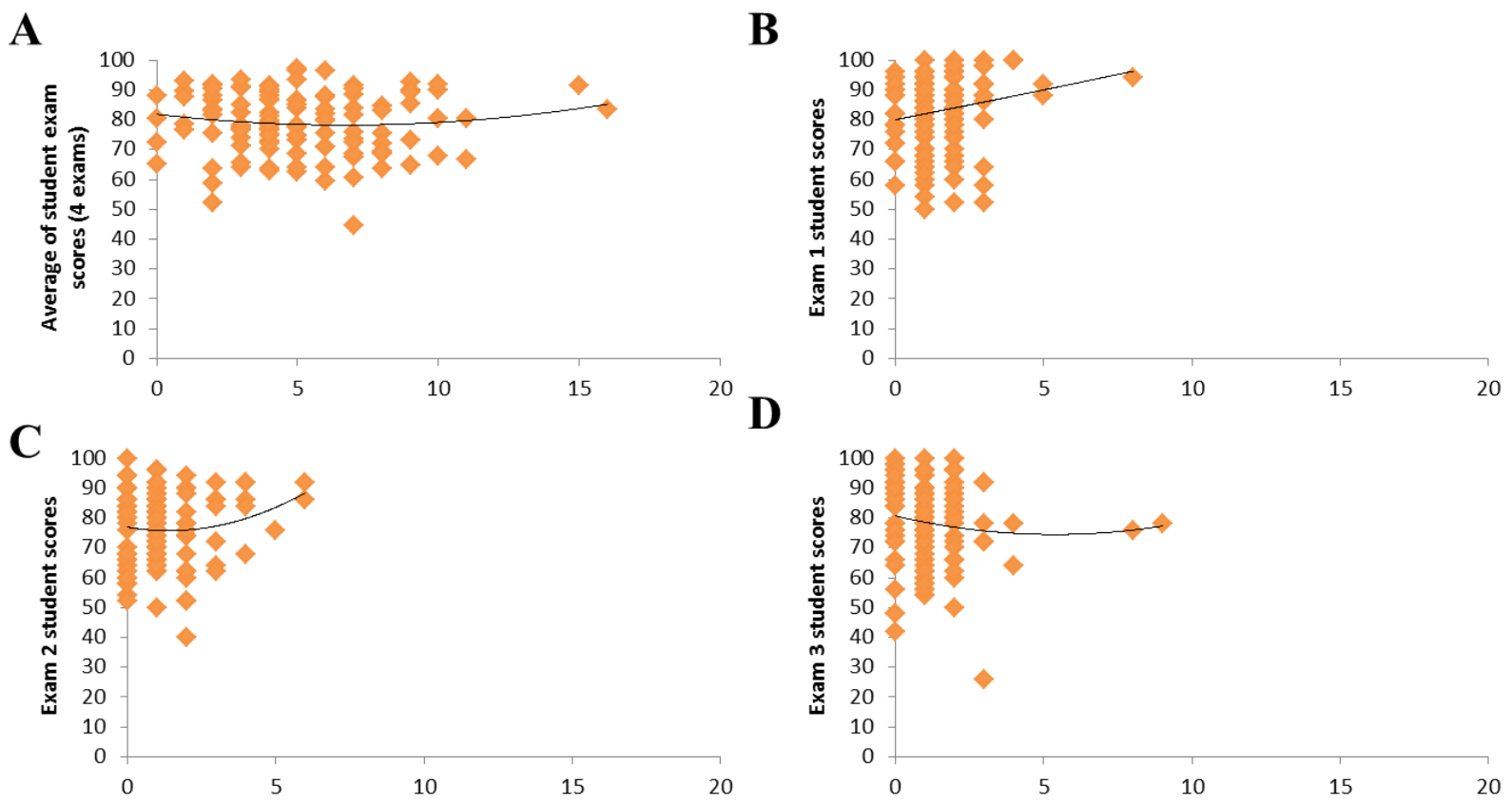

$\mathbf{E}$

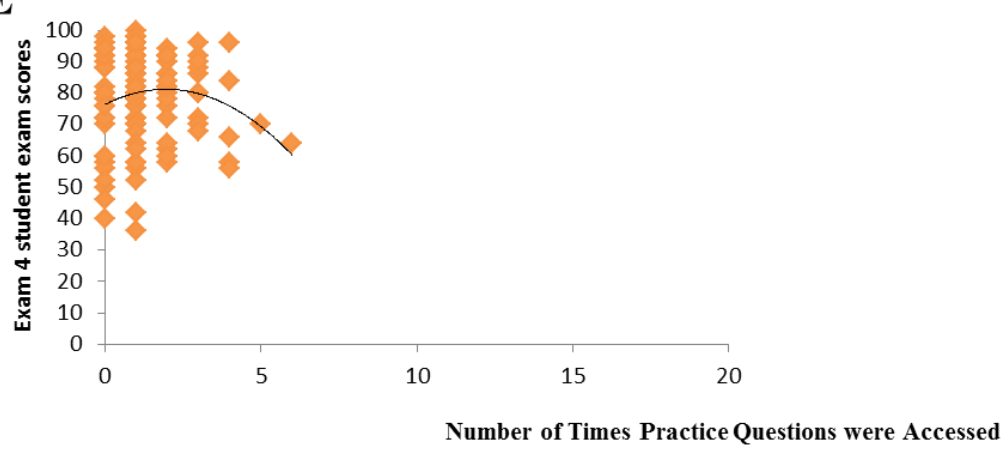

Figure 5. Correlation of number of times practice questions were accessed with student exam scores. Access to practice question files did not significantly correlate with the average of the overall unit exams (A). Only one unit (Exam 1) (B) showed a significant correlation between video file access and student exam scores ( $\rho: 0.21$, p: 0.01$)$. Correlations were determined using a non-parametric spearman-rho's ranked correlation test. Best fit lines were done using a third

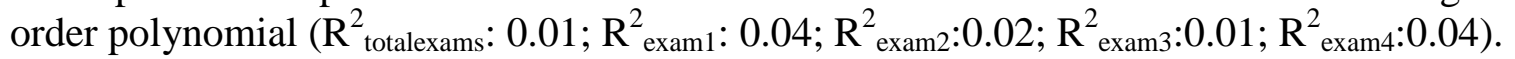




\section{Content Summaries}

Files were classified as a content summary if they explained a single concept (rather than an exam study guide). This included a nephron osmolality worksheet, a summary of the electrical activity of the heart, etc. Content summary files were only available for three of the four units.

Overall, number of times content summary files were accessed was significantly correlated with the averages of the three exams ( $\rho: 0.18, \mathrm{p}: 0.032)$. However, when individual exams were considered, content summary file accession number showed a significant correlation with only exam 1 scores ( $\rho: 0.32$, p: 0.0002). The other two exams did not show a significant correlation between content summary accession number and exam scores ( $p>0.05)$ (Figure 6).

\section{Lectures}

Lecture files were available for all four units, and the total number of times these files were accessed showed a significant effect on the averages of the four exam scores $(\rho: 0.2, p$ : 0.018). However, the number of times that lecture files were accessed was not significantly correlated with any of the individual exam scores $(\mathrm{p}>0.05)$ (Figure 6). 

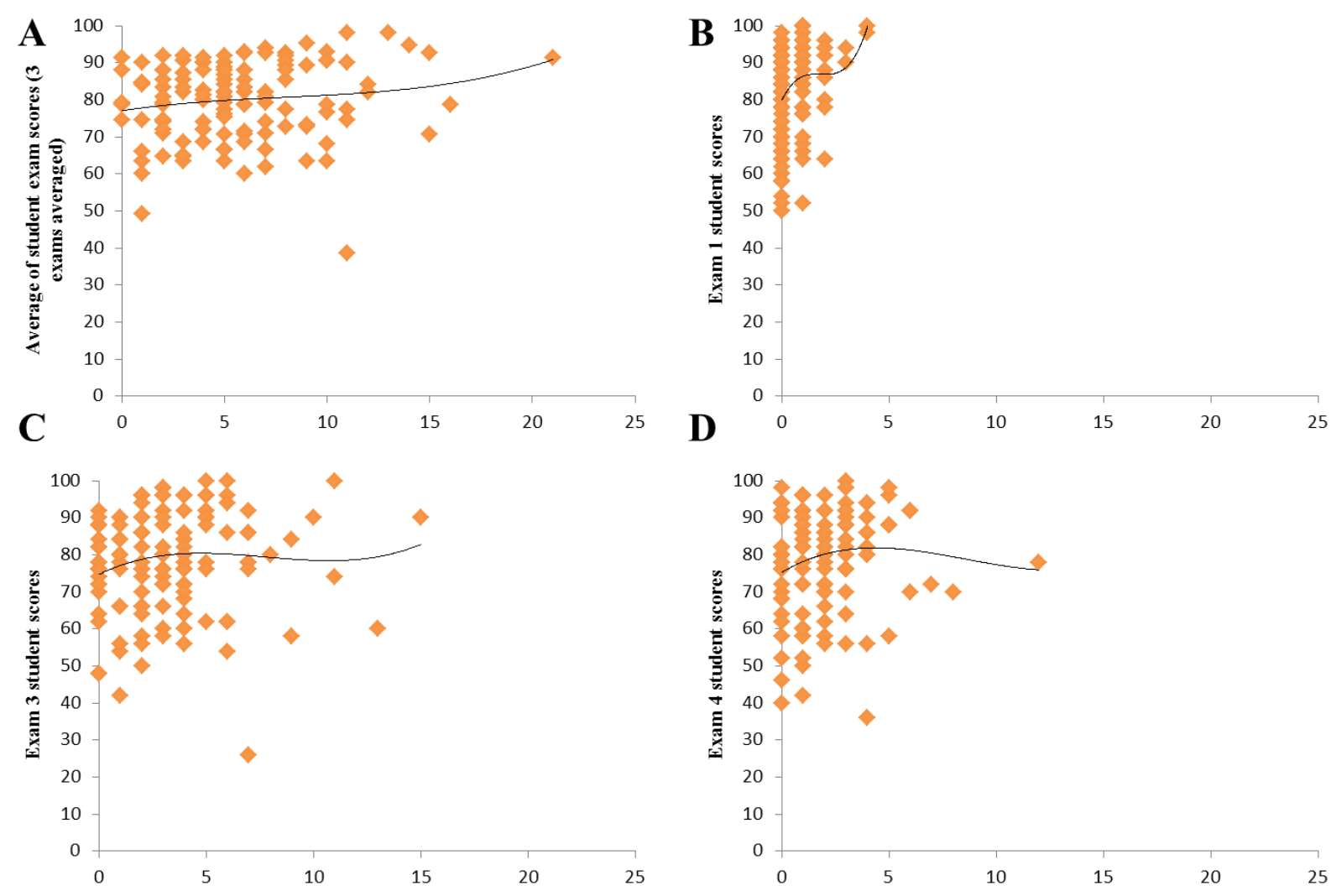

Number of Times Content Summary Files were Accessed

Figure 6. Correlation of number of times content summary files were accessed with student exam scores. Access to content summary files did not significantly correlate with the average of the overall unit exams where content summary files were available (3 units) (A). Only one unit (Exam 1) (B) showed a significant correlation between video file access and student exam scores ( $\rho: 0.32$, p: 0.0002). Correlations were determined using a non-parametric spearman-rho's ranked correlation test. Best fit lines were done using a fourth order polynomial $\left(\mathrm{R}_{\text {totalexams }}^{2}: 0.03\right.$;

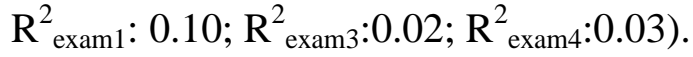


A
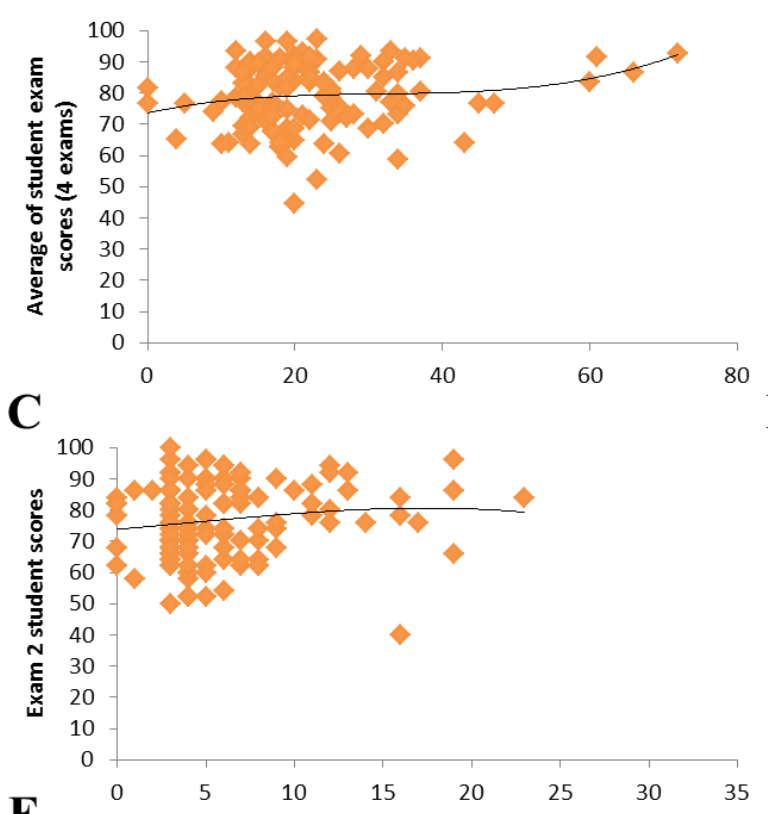

$\mathbf{E}$

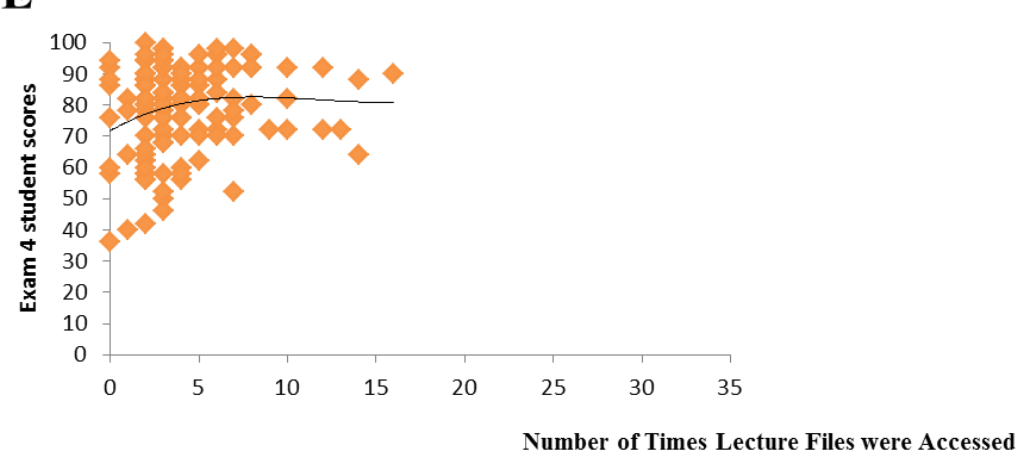

B

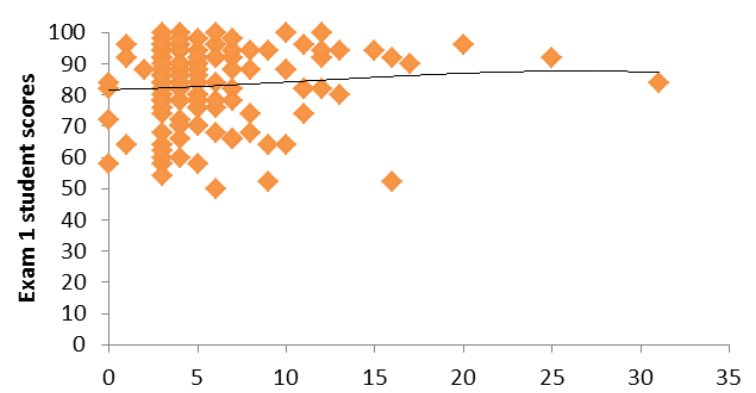

D

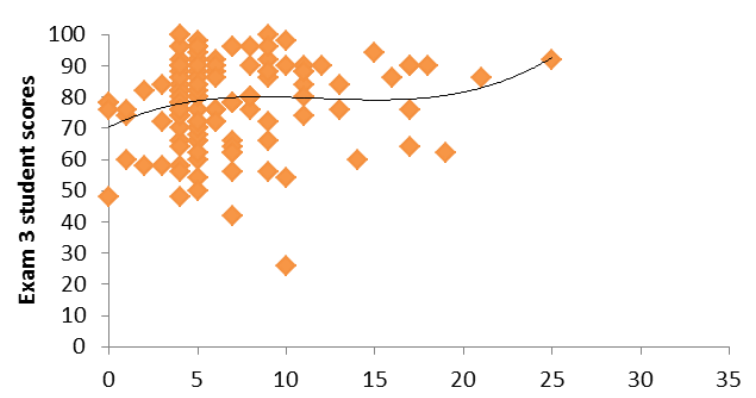

Figure 7. Correlation of the number of times lecture files were accessed with student exam scores. The number of times lecture files were accessed showed a significant correlation with the average of student exam scores for all four units ( $\rho: 0.2$, p: 0.018) (A). However, no individual unit exam (B-E) showed a significant correlation with times lecture files were accessed. Correlations were determined using a non-parametric spearman-rho's ranked correlation test. Best fit lines were done using a fourth order polynomial $\left(R_{\text {totalexams }}^{2} 0.04 ; R_{\text {exam } 1}^{2}: 0.009\right.$;

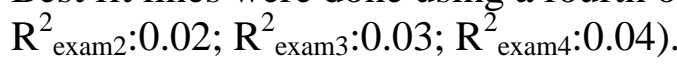


Chapter IV:

Discussion and Future Direction 


\section{Discussion}

The first call for changes in undergraduate science education prior to gaining entry to professional programs was published in 1910 by Flexner after he visited every existing medical school in the United States and Canada to evaluate the medical curriculum. A lack of core competencies (biology, chemistry, and physics) was noted in incoming medical students, preventing the students from mastering the medical curricula due to missing fundamental concepts. Medical education deficits were not revisited until the 1960s when Strassman et al. noted medical students were struggling with synthesizing information and applying it (1969). The current medical review is focusing on preparing pre-medical students more effectively for the medical school curriculum (AAMC, 2009). This is being done by revising the MCATs for 2015 and removing the requirement for pre-requisite courses. Instead, pre-medical students are focused on learning interdisciplinary competencies that integrate discipline-specific information. Focusing on these competencies also focuses students on demonstrating a mastery of critical thinking skills, such as information evaluation, ranking, and synthesis. This begins to address the continuing struggle of medical students' inability to use critical thinking skills effectively (Cooke, 2006; Lane, 2010; O’Callaghan, 2013; Pinto and Zeitz, 1997). Veterinary education took up the call for education reform in the 1980s, where it was noted that students leaving veterinary school were not adequately prepared for the daily rigors of their jobs (Pew Report, 1989). Similar to what Flexner (1910) noted, students have not yet mastered basic concepts when they begin the veterinary school curricula and struggle to succeed because they have to review concepts they should understand prior to gaining entrance to the professional programs. Both medical and veterinary education groups have identified a lack of student preparedness and inability to think critically or synthesize information. Both medical and veterinary education 
have independently suggested improving candidates from undergraduate science programs as important for improving the veterinary and medical fields.

Undergraduate science education reforms have focused on moving away from content heavy classrooms, which have grown increasingly cumbersome with the rapid gains in basic science and biomedical knowledge over the last several decades (AAAS, 2011; Knight and Wood 2005; Wood, 2009). Instead of attempting to only expose students to complex situations, such as molecular mechanisms, science education has focused on moving past factual recall into application of classroom material with conceptual learning (AAAS, 2011). Students leaving classrooms that focus on factual recall exhibit a lack of understanding in the discipline for the class they just took and the inability to use that information to think critically. This inability has been highlighted in both the original medical and veterinary calls for education, as well as follow-up summaries of curricular changes, and is now being addressed with more rigorous entrance exams (at least for medical schools) (AAMC, 2009; Cooke et al., 2006 Flexner, 1910; Pew Report, 1989; Radostits, 2003)

Both of these studies focused on conceptual learning and demonstrate that focusing on concepts in the classroom leads to an improvement in understanding course materials, as assessed by traditional summative exams. The educational intervention in the Invertebrate Zoology course highlighted an overall increase in student performance on a concept exam specifically designed for the course (Physiology concept exam; administered both at the beginning and at the end of the intervention period). The questions on this exam were designed to closely mimic professional school questions from three professions that require a fundamental understanding of physiology for daily clinical tasks. Learning gains derived from this test indicate students respond well to conceptual knowledge and are capable of assimilating the 
information in a short amount of time (the duration of the educational intervention was four 50 minute class periods). Learning gains show student performance increased on the exam between the initial and final exposure. In the second project, physiology concepts that were focused on through various media files on a Physiology course website explain a significant portion of the variation ( $\rho: 0.22, p: 0.01)$ in exam tests scores. This indicates that providing students with additional resources that explain fundamental concepts of physiology has the potential to improve students' understanding and may lead to increased exam scores.

Results from both studies require follow up studies to identify more accurately what changes are effective. With the educational intervention applied to the Invertebrate Zoology course, increasing time spent on the educational intervention (shorter individual sessions for the intervention over a longer period of time) may improve positive outcomes, and may also improve the students ability to process novel information. Although not statistically significant, the results from this study indicate focusing on fundamental concepts of physiology, such as gas movement, enabled students in a Invertebrate Zoology course to perform noticeably better on test questions written by professionals from medical, veterinary, and pharmacy fields. Results from the physiology course website indicate that providing extra study materials that focus on single, specific concepts may aid in student performance on exams. This can be interpreted as an increase in student learning. However, further studies should focus on creating a baseline for students at the beginning of the course and include previous coursework and exposure to physiology. Identifying any types of media that are more effective in explaining exam variation could also lead to informed changes in curricular extra study resources. 


\section{Physiology Education Intervention in a Basic Science Classroom}

Physiology has been highlighted as a discipline to maintain in undergraduate science programs as well as in liberal art schools (Feder, 2005). Physiology trains students to seek out and identify connections between it and other scientific/non-scientific disciplines (Feder, 2005). Learning physiology provides valuable critical thinking skills where students learn to apply information to situations (Miller et al. 2002). A physiology educational intervention was designed and introduced into an upper divisional biology elective course, Invertebrate Zoology. The comparative nature of the course incorporated a few aspects of fundamental physiology that were consistently highlighted across various phyla. This educational intervention was created to emphasize the integration of physiology into multiple fields, teach the students to draw on the comparative training they had received throughout the semester and apply their knowledge of physiological processes to novel scenarios about human physiology.

In this study, the educational intervention was designed using physiology to help emphasize the connections students have already gained in the classroom. The major thrust of the Invertebrate Zoology course required students to incorporate the knowledge from lectures into a single taxonomic key to use for organism identification on the final exam. This project required students to write their own compare and contrast couplets to distinguish between various phyla, classes, orders, and in some cases, species that were covered in lecture. One of the major ways to distinguish between the various invertebrate phyla involves differences in physiology, as well as anatomy of the organisms. Students began working on this project the first week of class, and continued to work on it until the educational intervention at the end of the semester. Most students identified themselves at the beginning of the semester as pursuing career paths in health professions and were taking the course as an upper divisional elective. 
Three professionals were asked to write questions that might be seen in physiology sections of their curricula. The three professionals were approached because they had either worked in their field or taught in the field (veterinary science, medicine, and pharmacy), and the professions were selected because physiology was a component of the professional program. Once the questions were written, they were sent to the course TA, keeping the instructor blind to the content of the test.

The educational intervention covered four 50 minute lecture periods. During the first and last lecture, students were given the pre-/post-test (same test, administered twice). This was administered on the first day by a TA and occupied 30 minutes of class time. The same amount of time was allotted for the same exam during the fourth class period when the TA administered it again. Students were informed that participation was not required, and they would not receive a grade that affected their grades. However, participation was incentivized, with bonus points on the final exam being made available to any student that took both the pre- and post-test. The same days that the exam was administered, students were also sent a link to answer an online questionnaire, where they were asked to rank their self-confidence answering the three physiology questions. Each of the four intervention periods included a 20 minute lecture followed by group work and probing questions led by the instructor. These lectures focused on basic concepts that underlie physiology and focused students on human physiology. Connections were made during the lectures to the physiology that students had been exposed to during the course. Improvements, although not statistically significant (perhaps due to the small sample size), between the students' performance on the two exams was quantified using the equation: Normalized learning gains $=[($ post test score - pre test score $) /($ total number of questions - pre test score $)] * 100$ from Wood and Knight (2005).This equation enabled the calculation of learning gains, which quantifies score improvement on an identical test before and after an educational intervention. 
Overall learning gains ( $\mathrm{M}_{\text {med }}: 15.3 \% ; \mathrm{M}_{\text {pharm: }}$ 5.6\%; $\left.\mathrm{M}_{\mathrm{vet}}: 5.6 \%\right)$ increased, but there was no significant difference between the questions written by the three professionals. There was a significant amount of variation within each of the groups, likely due to the small population size of the class.

It has been suggested that focusing students on factual content of a course does not translate into a gain of critical thinking skills (Carvahlo and West, 2012). Students have to be able to use and apply the information they are learning to gain a deeper understanding of a discipline necessary to begin to problem solve in that field (Dobson, 2011). This study used a physiology educational intervention to draw connections to human physiology and solidify the connections they were already making with comparative physiology. Focusing on human physiology provided a capstone for students, as something they could relate to both on a personal level and from career goals that connected through every phylum that had been taught in an upper divisional survey of a zoological field. This allowed students to better comprehend the knowledge framework they had constructed throughout the course and utilize it in a related, but foreign field (human physiology) (Krontiri-Lewis, 2003, Peterson et al. 1985). This intervention highlighted a few, basic concepts in physiology that drove home connections between fields. The positive learning gains indicate that students were able to make connections between comparative physiology and assimilate concepts that encompassed human physiology, using them to understand novel ideas and questions that were presented in a similar fashion to professional school exam questions. 


\section{The Effects of a Multimedia Approach Focusing on Concepts in a Physiology Classroom}

Although physiology has been highlighted as a scientific discipline to maintain in liberal arts education, it has often been targeted for removal from the curriculum because it is a subject in which students often struggle (Feder, 2005). Physiology is useful because it trains students to make connections between topics, and can be used as a tool to teach critical thinking skills (Miller et al. 2002; Peterson, 1985). However, to use physiology to teach students how to think critically, students must be capable of thinking about various aspects of a complex system (Peterson, 1985). Using computers to present facets of physiological concepts in a multimedia fashion allows students to explore the multiple layers of thought required to comprehend a concept (Marée et al. 2013). Additionally, students are capable of controlling the speed at which they move through computer based information, allowing them to spend as much or as little time as they need on any concept (Marée et al. 2013). Finally, it has been shown that students using computer animations and other supporting materials outperform students that do not access these same animations (Ardac and Akaygun, 2004). In the current study, we assessed whether providing access to multimedia files as additional study aides is of benefit to learning in an upper divisional physiology course.

During four exam periods (the length of instruction for one instructor), students were allowed access to several different file types in the online part of the course. These files included audio and video files, content summary worksheets, practice questions, as well as lectures. Students were not required to access the files, but they were made available for students to use if they wanted. Dates of access and number of times students accessed these files were obtained from the West Virginia University Health Sciences IT Department. The data were separated by student, exam, and the number times prior to an exam students accessed those files. 
The number of times any file type was accessed was summed for all four exams and correlated with the average of all four exams. The total number of times audio files, total number of content summary files accessed, and total number of lecture files accessed were all correlated with the averages of the four exams in which the study materials were made available. A significant amount of variability in the average of exam scores was explained by the number of students accessed all types of files ( $\rho: 0.22, \mathrm{p}: 0.01)$. The content summaries were an average of three, instead of four exams, because that specific type of file was not available for one exam (exam two). A possible explanation is that these multimedia files focused students on fundamental concepts, allowing the students to master these, and use this understanding to answer test questions with different content but the same concept. An alternate explanation is that the multimedia files were accessible to the students outside of lecture periods, allowing the students to study at their individual paces.

The number of times audio files were accessed explained a significant amount of variability for scores on each of the four exams. These files were designed and recorded by the instructor to supplement the lecture, and each focused on a single concept. This would support the possibility that students were focusing on conceptual learning rather than content learning. The number of times content summaries were accessed only significantly explained variability during exam one. The other two exams where content summaries were available (exams three and four) did not have a significant amount of variability in scores explained by content summary access. Both the number of times video files and practice questions were accessed only had a significant effect on the first exam (video files were not available for exam two). A potential explanation for why these types of files were only significantly correlated with the first exam could be that students were more concerned with performance during the first exam, 
therefore they studied harder, but then became complacent or busy as the semester progressed. The class average for the first exam was higher than the subsequent three exams taught by the instructor. However, the content was different for each exam, which could explain, in part, the difference in class exam averages for each unit. The audio files were significantly correlated with every exam score but the video files were only significantly correlated with the first exam. This pattern might be explained because the audio files were written and recorded by the instructor, but the video files were found on the internet, and may not have been as conceptually focused.

Each file type, independent of its multimedia type, was designed by the instructor to explain a single concept, with the exception of video files. These multimedia files, taken as a unit within a group, were created to help students understand challenging concepts in more detail than was covered in lecture. Audio files had significant effects on every exam. With the exception of lecture files, the other file types all had significant effects during one exam. However, when summed together, the varying compositions of files students chose to use had significant effects on every single exam. These files may have allowed students to focus on important physiological concepts without being overwhelmed by content. Alternatively, this may suggests that students were capable of moderating their own pace and style of learning, which could contribute to the overall significant effects that accessing multimedia files had on exam scores (Marée et al. 2013). Focusing students on concepts that were challenging, providing them with a deeper explanation than could be achieved during lecture, and providing a general framework for the students to link the concepts together (by presentation in different folders on the website), may enable students to create individualized virtual concept maps or study guides to augment their learning (Krontiri-Lewis, 2003; Marée et al., 2013). The individual use of multimedia files may allow students to select for information in a learning style that is 
preferential for them. Moreno (2002) points out that multimedia files containing different terminology and symbols may actually be detrimental by exhausting functional mental capacity. Thus, alternating between types of multimedia files may actually decrease the learning capacity of the student (Nugent, 1982).

\section{Future Directions}

\section{Physiology Education Interventions in a Basic Science Classroom}

This study was designed to focus on concepts that were already being taught in a basic science classroom, expanding the scope of comparative physiology from invertebrate phyla to include human physiology. This was done by focusing on core concepts that continually emerged throughout the course such as respiratory and cardiovascular physiology. The physiology intervention emphasized assimilation of knowledge from the classroom to a more relatable subject for the students, both personally as well as for self-identified career goals. The intervention quantified whether students were able to perform better in responding to prototypical medical, veterinary, and pharmacy questions. Only slight overall improvements were observed and no significant differences in performance were seen between types of questions. Associations between student learning gains and student confidence indicated student confidence did not change over the course of the educational intervention. This indicates that even though student performance improved slightly, students' perception of their abilities did not improve. Student self-evaluation of performance tends to be biased by both their perception of what a test is assessing and their previous experiences with the subject they think the test is evaluating. Depending on student perception, their predictions are often independent of actual performance (Ehrlinger and Dunning, 2003). The lack of an association could be due to a lack of 
time for students to develop appropriate self-evaluation, which involves feedback. Students were not given any feedback, other than answers in class to group questions, over the short period of time the educational intervention occurred. Placing the educational intervention at the end of the semester introduced a time constraint that may have prevented students from gaining confidence over a longer period of exposure to the material. One factor that led to this time constraint was obtaining questions from the professionals. Each professional was currently working in their fields and graciously volunteered to write multiple choice test questions in their spare time, which resulted in receiving the questions just prior to the end of the semester. Because of these time constraints, as well as those in the classroom, only a few questions were obtained from the professionals resulting in a small sample size for each type of question. Logical next steps would be to construct a concept exam prior to the beginning of the semester, enabling it to be given to the students earlier in the semester, and the educational intervention could then be integrated more fully into the classroom over the course of the semester. One of the larger student populations identified the dental field as their career goals. Given more time, a dental professional needs to be approached and questions similar to dental school physiology questions should also be integrated into the educational intervention. It was noted there were differences in the question construction between fields. Questions from the medical and veterinary fields only used four options (A-D) while questions from pharmacy used six options (A-F) that included options for multiple right answers and an option for no right answer. Given more time, the questions could be screened and modified for uniformity. It is expected that by incorporating these changes, most notably increasing the time spent in the classroom on the intervention and in designing/expanding the concept exam, student learning gains and confidence in their ability to integrate the information to respond to foreign questions would likely increase. Lastly, the 
student population in the class was small $(n=23)$ and there was high variance seen in the data set. Assuming other classrooms would have a similar distribution of variables such as ethnicity, educational background, etc. a retrospective power analysis of question category indicates a student population of 100 would yield a power of $89 \%$ with a p-value of 0.05 . Similarly, a retrospective power analysis of student learning gains by self-identified career choice indicates that a student population of 120 students would have a greater power (88\%) with a p-value of 0.05. The retrospective power analyses indicate that introducing this educational intervention might yield statistically significant results in a classroom with a larger student population. However, retrospective power analyses are only approximations and assume that all variables are the same. With a large population of students, there are bound to be differences in ethnicity, gender, and educational background that would have to be controlled for in the classroom.

\section{The Effects of a Multimedia Approach Focusing on Concepts in a Physiology Classroom}

This study was designed to evaluate the effects of providing students with additional multimedia materials on their exam performance. The total number of times a content file was accessed was summed, both within an exam, and across all four exams when the files were available (content summaries and video files were only available for three out of the four exams). However, the data only provided a time stamp for when the information was accessed. Total time spent with the material was unquantifiable using just the online data tracking. Future studies should take this into account and tag the data so the total time files are open is also evaluated. Since students are capable of opening a file in a tab on their browser, and then opening additional tabs and doing other tasks, a threshold of time would have to be set for each of the opened files. Anything beyond that threshold would be discarded and not included in subsequent statistical analyses. It would be interesting to determine how individual student performance was affected by accessing 
these multimedia files. A baseline for each student would have to be established at the beginning of the semester with a concept exam, which would also be administered at the end of the course, or at the end of the sections in which the multimedia files were provided. This could establish whether students improved using the multimedia files, and which type of media was the most beneficial. Student demographics would also have to be taken into account, including any prior coursework in physiology. Due to Federal Educational Rights and Privacy Act (FERPA) restrictions, ACT/SAT scores and overall student GPAs were not possible covariates. Including these as variables may, at least partially, predict student performance in the class regardless of file access. Finally, the impact of this work could be strengthened if the class was split - with half provided the files and the other half not provided access to the files. There could be adherence issues with this design, because students will talk and potentially share access to the files, creating a potential confounding factor. A potential way to alleviate this would be to provide multimedia files to the students in the upper divisional physiology course one year, and then not provide the files for the students the following year. Another approach would be to only provide multimedia files to students for half of the units, and only provide lectures and review questions for the other half of the units. Either of these approaches would allow for a more robust comparison of how accessing the multimedia files effects student grades.

Accessing multiple types of multimedia files may be detrimental to the student (Nugent, 1982; Moreno, 2002). Restricting what types of multimedia files were accessible could be done to determine if certain types of multimedia files were more effective at improving student understanding of concepts covered on the exams. However, the fact that the audio files were designed and recorded by the instructor and the video files were not presents a confounding variable. Video files would either have to be written by the instructor, or audio files would have 
to be taken from the internet (found online by content the same way as the video files were) to remove the instructor's confounding effect. Individuals have different learning styles, and providing multimedia files allows students to gravitate towards their preferred learning style. This circumvents having to inventory and control for all student learning styles that would have to be taken into account when determining which types of multimedia files were more effective. Finally, because the content on the different unit exams the instructor taught had varying levels of difficulty, performance might naturally be different based on the material. To control for this, a comparison across semesters where different cohorts of students performed on the same test could be used as a comparison. 


\section{Literature Cited}

1. Alpern RJ, Belitsky R, and Long S (2011) Competencies in the Premedical and Medical Education: The AAMC-HHMI Report. Perspectives in Biology and Medicine, 54(1): 30-35.

2. American Association for the Advancement of Science (AAAS) (2011) Vision and Change in Undergraduate Biology Education A Call to Action. Directorate for Education and Human Resources: Division of Undergraduate Education and the Directorate for Biological Sciences, Washington DC. Retrieved from: http://visionandchange.org/files/2013/11/aaas-VISchange-web1113.pdf

3. Allen, D and Tanner, K (2005) Infusing Active Learning into the Large-enrollment Biology Class: Seven Strategies, from the Simple to the Complex. Cell Biology Education, 4: 262-268.

4. Al-Krenawi, A (2005) Socio-political aspects of mental health practice with Arabs in the Israeli Context. Israeli Journal of Psychiatry and Related Science, 42(2): 126136.

5. Andrews K, Chaddock M, and Osburn, BI (2013) Baseline survey of progress by veterinary medical colleges in implementing recommendations from the North American Veterinary Medical Education Consortium. Journal of American Veterinarian Medical Association, 243(6): 826-832.

6. Angelo TA, and Cross KP (1993) Classroom Assessment Techniques: A Handbook for College Teachers. $2^{\text {nd }}$ ed. Jossey-Bass, San Francisco, CA.

7. Ardac D and Akaygun S (2004) Effectiveness of Multimedia-Based Instruction That Emphasizes Molecular Representations on Students' Understanding of Chemical Change. Journal of Research in Science Teaching, 41(4): 317-337.

8. Association of American Medical Colleges (AAMC) (1983) Emerging Perspectives on the General Professional Education of the Physician: Problems, Priorities, and Prospects. Kaiser Foundation

9. Association of American Medical Colleges (AAMC) (2009) Scientific Foundations for Future Physicians: A report of the AAMC-HHMI Committee. Retrieved from: http://www.udel.edu/qbio/careers/08-209_AAMC-HHMI_report.pdf

10. Baker R (2006) Health management with reduced antibiotic use - the U.S. experience. Animal biotechnology, 17:195-205.

11. Barrows HS (1985) How to Design a Problem-based Curriculum for the Preclinical Years. New York: Springer.

12. Barrow HS (1986) A taxonomy of problem-based learning methods. Medical Education, 20(6): 481-486.

13. Barrington GM, and Allen AJ (2010) Food Animal Veterinarians: Where We Came From and Where We Might Go. The online journal of rural research and policy, 5(7): $1-7$. 
14. Baskas, R (2012) Compare and Contrast Principles of Practice, ERIC database, in process of publication

15. Bloom BS, Engelhart MD, Furst EJ, Hill WH, Krathwohl DR (1956) Taxonomy of education objectives: the classification of educational goals, by a committee of college and university examiners. Handbook I: cognitive domain. David McKay Company, Inc., New York, NY.

16. Bonwell, CC and Eison, JA (1991) Active Learning: Creating Excitement in the Classroom, ASHE-ERIC Higher Education Report No. 1. Washington, DC: The George Washington University, School of Education and Higher Education.

17. Brody DS (1980) Physician Recognition of Behavioral, Psychological, and Social Aspects of Medical Care. Archive of Internal Medicine. 140(10): 1286-1289.

18. Brouet S, Cichowicz M, Jakubowski HV, and Zapanta LS (2013). Instructional Resources for the New MCAT Exam Available at the Open-Access, Pre-Health Collection with MedEDPORTAL's iCollaborative. Journal of Chemical Education, 90: 1697-1698.

19. Brown, RE (1979) Rockefeller Medicine Men: Medicine and Capitalism in America. University of California Press, Berkley and Los Angeles, CA.

20. Calman K (1994) The Profession of Medicine. British Medical Journal, 309: 11401143.

21. Carvalho and West (2011). Voluntary participation in an active learning exercise leads to a better understanding of physiology. Adv Physiol Edu, 35: 53-58

22. Crowe A, Dirks C, and Wenderoth MP (2008) Biology in Bloom: Implementing Bloom's Taxonomy to Enhance Student Learning in Biology. CBE - Life Sciences Education, 7: 368-381.

23. Dobson (2011). Effect of selected "desirable dificulty" learning strategies on the retention of physiology information. Adv Physiol Edu, 35: 378-383.

24. Ehrlinger J and Dunning D (2003) How Chronic Self-Views Influence (and Potentially Mislead) Estimattes of Performance. Journal of Personality and Social Psychology, 1: 15-17.

25. Escribano BM, Aguera EI, and Tovar P (2011) Designing an Interactive Activity to Integrate Animal Physiology in the Context of Different Disciplines. Advancements in Physiology Education, 35: 464-465.

26. Evidence Based Medicine: A new approach to teaching the practice of medicine (1992) Journal of American Medical Association, 268(17): 2420-2425.

27. Eyre P (2002) Engineering Veterinary Education. Journal of American Veterinary Medical Association, 29(4): 195-200.

28. Feder, ME (2005) Aims of Undergraduate Physiology Education: A View from the University of Chicago. Advancements in Physiology Education, 29: 3-10.

29. Felder, RM and Brent, R (1996) Navigating the Bumpy Road to Student-Centered Instruction. College Teaching, 44(2):43-47. 
30. Flexner, A (1910) Medical Education in the United States and Canada. The Carnegie Foundation for the Advancement of Teaching.

31. Fosgate, GT (2008) Veterinary Student and Veterinarian Attitudes toward Veterinary Public Health and Epidemiology. Journal of American Veterinary Medical Association, 233(2):240-247.

32. Gaytan S and Pasaro R (2009) The Combined used of e-Learning and Traditional Learning Systems for Students of Biology and Biochemistry. Proceedings of the European Conference on e-Learning, 212-218.

33. Goldman, L (2004) Modernizing the Paths to Certification in Internal Medicine and its Subspecialities. The American Journal of Medicine, 117: 133-136.

34. Gough KC (2011) Enhanced podcasts for teaching biochemistry to veterinary students. Biochemistry and Molecular Biology Education, 39(6): 421-425.

35. Handelsman J, Miller S, and Pfund, C (2007) Scientific Teaching. Roberts and Company Publishers, New York, NY.

36. Harris DL and Lloyd JW (2011) Changes in teaching of nontechnical skills, knowledge, aptitudes, and attitudes at US colleges and schools of veterinary medicine between 1999 and 2009. Journal of Veterinary Medical Education, 239(6): 762-766.

37. Henry C and Treanor L (2010) Entrepreneurship education and veterinary medicine: enhancing employable skills. Education+training, 52(8/9): 607-623.

38. Hoppe A and Trowald-Wigh G (2000) Student versus Faculty Attitudes toward the Veterinary Medical Profession and Education. Journal of Veterinary Medical Education, 27(2):17-23.

39. Kogan, LR and McConnell, S (2001) Gaining Acceptance into Veterinary School: A Review of Medical and Veterinary Admissions Policies and Practices. Journal of Veterinary Medical Education, 28(3):101-110.

40. Knight JK, and Wood, WB (2005) Teaching More by Lecturing Less. Cell Biology Education, 4: 298-310.

41. Krathwohl DR, Bloom BS, and Masia, BB (1964) Taxonomy of education objectives: the classification of education goals. Handbook II: Affective Domain. David McKay Company, Inc. New York, NY.

42. Krathwohl, DR (2002) A Revision of Bloom's Taxonomy: An overview. Theory in Practice, 41(4): 212-218.

43. Krontiris-Litowitz (2003). Using manipulatives to improve learning in the undergraduate neurophysiology curriculum. Adv Physiol Edu, 27: 109-119

44. Lane IF (2010) Professional competencies in health sciences education: from multiple intelligences to the clinic floor. Advances in Health Science Education, 15: 129-146.

45. Lloyd, JW (2007) Enhancing Nontechnical skills, knowledge, aptitudes, and attitudes in the veterinary profession through the work of the National Commission on Veterinary Economic Issues. Journal of American Veterinary Medical Association, 230(11): 1646-1652. 
46. Lodish, HF and Rodriguez, RK (2004) A Combination of Lectures, Problem Sets, and Recitation Sections is an Excellent Way to Teach Undergraduate Cell Biology at a High Level. Cell Biology Education, 3: 202-204.

47. Marée TJ, van Bruggen JM, Jochems WMG (2013) Effective self-regulated science learning through multimedia-enriched skeleton concept maps. Research in Science and Technological Education, 31(1): 16-30.

48. Marshak, RR (2005) Veterinary schools and the profession: a search for bearings in the new century. Journal of American Veterinarian Medical Association, 227(8): 1234-1238. Academic Medicine 75(4): 362-368.

49. McGaghie WC, McCrimmon DR, Thompson JA, Ravitch MM, and Mitchell G (2000) Medical and Veterinary Students' Structural Knowledge of Pulmonary Physiology Concepts. Academic Medicine, 75(4): 362-368.

50. Mededportal iCollaborative page. Retrieved June 12, 2014, from https://www.mededportal.org/icollaborative/190142/search.html?q=prehealth $\& \mathrm{p}=1 \& \mathrm{t}=\mathrm{p}$

51. Michel N, Cater III JJ, Varela O (2009) Active versus passive teaching styles: An empirical study of student learning outcomes. Human Resource Development Quarterly, 20(4): 397-418.

52. Moreno, R (2002) Who Learns Best with Multiple Representations? Cognitive Theory Implications for Individual Differences in Multimedia Learning. World Conference on Educational Media.

53. Moskowitz J and Thompson JN (1999) Setting better priorities for medical education. Academic Medicine, 74(5): 461-462.

54. Murphy, FA (2008) Emerging zoonoses: The challenge for public health and biodefense. Preventive Veterinary Medicine, 83: 216-223.

55. Nugent, GC (1982) Pictures, Audio, and Print: Symbolic Representation and Effect on Learning. Educational Communication and Technology Journal, 30(3): 163-174.

56. O'Callaghan A (2013) Emotional congruence in learning and health encounters in medicine: addressing an aspect of the hidden curriculum. Advances in Health Science Education, 18: 305-317.

57. Osburne B, Scott C, and Gibbs P (2009) One world- One medicine - One health: Emerging Veterinary Challenges and Opportunities. Scientific and Technical Review of the Office International des Epizooties, 28(2): 481-486.

58. Pellegrini CA, Warshaw AL, and Debas HT (2004) Residency Training in Surgery in the $21^{\text {st }}$ Century: A New Paradigm. Surgery, 136(5): 953-965.

59. Peterson NS, Campbell KB, and Armstrong DR (1985) A Pedagogical Challenge: Integrative Thinking. National Institute of Education, Washington DC.

60. Petri, E and Kohlbl, H (2004) Eminence, or rather eloquence, or rather economybased medicine. International Journal of Urogynecology and Pelvic Floor, 15: 147148. 
61. Pinto AJ and Zeitz HG (1997) Concept mapping: a strategy for promoting meaningful learning in medical education. Medical Teacher, 1(2): 114-121.

62. Posner GJ, Strike KA, Hewson PW, and Gertzog WA (1982) Accommodation of a Scientific Conception: Toward a Theory of Conceptual Change. Science Education, 66(2): 211-227.

63. Pritchard, Richard (1989) Future Directions for Veterinary Medicine. Duke University: PEW National Veterinary Education Program. Durham, NC.

64. Pugente, MD and Badger, RA (2003). Teaching Introductory Organic Chemistry: 'Blooming Beyond a Simple Taxonomy. Journal of Chemical Education, 80(7): 779784.

65. Radostits O (2003) Engineering Veterinary Education: A Clarion Call for Reform in Veterinary Education - Let's do it! Journal of Veterinary Medical Education, 30(2): 176-190.

66. Sachdeva, AK (1996). Preceptorship, mentorship, and the adult learner in medical and health sciences education. Journal of Cancer Education, 11(3): 131-136.

67. Sackett DL, Rosenberg WMC, Gray J, Haynes RB, and Richardson, WS (1996) Evidence Based Medicine: what it is and what it isn't. British Medical Journal, 312: 71-72.

68. Sturdy, S (1992) The political economy of scientific medicine: science, education, and the transformation of medicinal practice in Sheffield 1890-1922. Medical History, 36: 125-159.

69. Schwerdt, G and Wuppermann, AC (2009) Is traditional teaching really all that bad? : a within-student between-subject approach. CESifo working paper, no. 2634, URL: http://handle.net/10419/30604

70. Strassman HD, Dax Taylor D, and Scoles J (1969) A New Concept for a Core Medical Curriculum. Academic Medicine, 44(3): 170-177.

71. Tanner, K and Allen, D (2004) Approaches to Biology Teaching and Learning: Learning Styles and the Problem of Instructional Selection - Engaging all Students in Science Courses. Cell Biology Education, 3: 197-201.

72. Wilke, RR (2003) The Effect of Active Learning on Student Characteristics in a Human Physiology Course for Nonmajors. Advancements in Physiology Education, 27(4):207-223.

73. Wood, WB (2009) Innovations in Teaching Undergraduate Biology and Why We Need Them. Annual Reviews of Cell and Developmental Biology, 25: 93-112.

74. Wood, WB and Handelsman, J (2004) Meeting Report: The 2004 National Academies Summer Institute on Undergraduate Education in Biology. Cell Biology Education, 3:215-217.

75. Zheng AY, Lawhorn JK, Lumley T, and Freeman S (2008) Application of Bloom's Taxonomy Debunks the "MCAT Myth." Science, 319: 414-415. 
Appendix

Pre- and Post-Test

Pre- and Post-Questionnaire 
Questions from the pre- and post-test were written by professionals in their fields. Professionals were approached by phone/email. Once they had graciously agreed to contribute to the test, they were emailed a topic list of physiology topics that were touched on during the class. A medical school instructor wrote four questions similar to what was seen in medical school physiology courses. A practicing pharmacist and Ph.D. wrote five questions similar to physiology questions seen in pharmacy school physiology classes. A practicing veterinarian wrote three questions similar to physiology questions seen during veterinary school. 


\section{Medical Questions}

Multiple Choice Questions

1) As blood moves through systemic capillaries passing by exercising muscle what happens to the affinity of hemoglobin for oxygen and what happens to the $\mathrm{Hb}-\mathrm{O}_{2}$ dissociation curve?
a. Hb affinity for $\mathrm{O} 2$ increases and the dissociation curves shifts to the left
b. Hb affinity for $\mathrm{O} 2$ increases and the dissociation curves shifts to the right
c. Hb affinity for $\mathrm{O} 2$ decreases and the dissociation curves shifts to the left
d. Hb affinity for $\mathrm{O} 2$ decreases and the dissociation curves shifts to the right

\section{Correct answer: D.}

2) In mammalian lungs Boyle's law is the underlying basis for the movement of air during inspiration and expiration. Assuming breathing at sea level, which of the following is true during inspiration?
a. Pleural pressure is positive relative to atmospheric
b. Alveolar pressure equals atmospheric pressure
c. Alveolar pressure is higher than atmospheric pressure
d. Pleural pressure is more negative than it is during expiration

Correct answer: D.

3) Carbon monoxide poisoning results in significant hypoxia by both decreasing the amount of oxygen carried by the blood and causing a left shift in the oxygen-hemoglobin dissociation curve. Which of the following treatment is best used to reverse this condition?
a. breathing normal air at twice atmospheric pressure
b. breathing 50\% oxygen at a sea level atmospheric pressure
c. breathing normal air in combination with an increased plasma $\mathrm{pH}$
d. giving a blood transfusion to add more hemoglobin to bind more oxygen

Correct answer: B. 
4) The figure below depicts the hydrostatic pressure profile existing across the vascular tree starting from the heart at left, and back to the heart at right. Which of the following vessel types best matches vessel type/level B (shaded)?

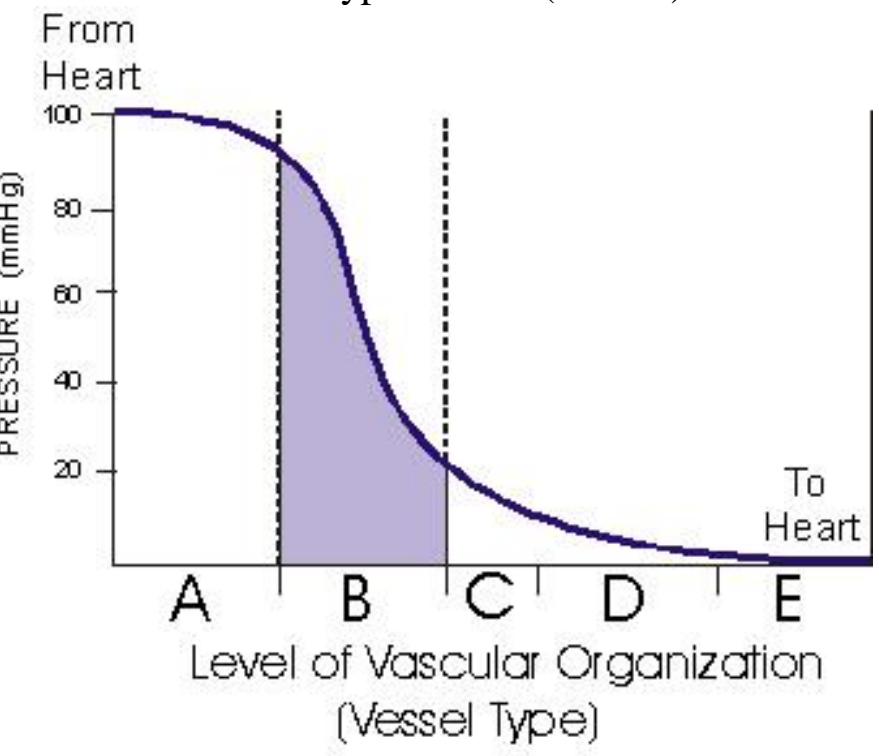
a. veins
b. capillaries
c. arterioles
d. major elastic arteries

Correct answer: $\mathrm{C}$ 


\section{Pharmacy Questions}

Erythrocyte production is stimulated by low blood oxygen levels, typical causes of which are:
a. Decreased numbers of erythrocytes
b. Decreased or defective hemoglobin
c. Increased tissue demands for oxygen
d. Two of the above
e. All of the above
f. None of the above

Correct Answer: E, all of the above.

\section{Citation:}

Seeley, R., et al. (1998). Cardiovascular System: Blood, found in: Anatomy and Physiology, $4^{\text {th }}$ ed, Tibbetts, K.N., Rossman, B.J., Ernzen, B.A., editors. McGraw-Hill, Boston, MA pp. 576600 .

Oxygen $\left(\mathrm{O}_{2}\right)$ delivery to a particular tissue is dependent on:
a. The amount of $\mathrm{O}_{2}$ entering the lungs
b. The adequacy of pulmonary gas exchange
c. The blood flow to the tissue
d. Two of the above
e. All of the above
f. None of the above

Correct Answer: E, all of the above.

Citation:

Ganong, W.F. (1997). Gas Transport Between the Lungs \& the Tissues, found in: Review of Medical Physiology $18^{\text {th }}$ ed., Butler, J.P, Suver, A.M., Langan, C., editors. Appleton \& Lange, Stamford, CT, pp. 621-625.

A pharmaceutical company is developing a new drug to reduce high blood pressure. Which of the following would be an effective mechanism for the new drug to target to reduce blood pressure:
a. A drug that increases heart rate
b. A drug that decreases stroke volume
c. A drug that decreases peripheral resistance
d. Two of the above
e. All of the above
f. None of the above

Correction Answer: D (B\&C) 
Citation:

Seeley, R., et al. (1998). Cardiovascular System: Peripheral Circulation and Regulation,found: in Anatomy and Physiology, $4^{\text {th }}$ ed, Tibbetts, K.N., Rossman, B.J., Ernzen, B.A., editors. McGrawHill, Boston, MA pp. 641-696.

Characteristics of molecules that favor its ability to cross cell membranes include:
a. Low molecular weight
b. Ionization (charged)
c. High lipid solubility
d. Two of the above
e. All of the above
f. None of the above

Correct Answer: D (A\&C)

Citation:

Hollenberg, P.F., \& Brody, T.M. (1998). Absorption, Distribution, Metabolism, and Elimination, found in: Human Pharmacology, Molecular to Clinical, $3^{\text {rd }}$ ed. Brody, T.M., Larner, J., Minneman, K.P., editors. Mosby-Year Book, Inc. Saint Louis, MO pp. 35-46.

Chemical mediators for intercellular communication can be transmitted:
a. Across the synaptic cleft
b. Via gap junctions directly from cell to cell
c. By circulating body fluids
d. Two of the above
e. All of the above
f. None of the above

Correct Answer: E, all of the above

Citation:

Ganong, W.F. (1997). The General \& Cellular Basis of Medical Physiology, found in: Review of Medical Physiology $18^{\text {th }}$ ed., Butler, J.P, Suver, A.M., Langan, C., editors. Appleton \& Lange, Stamford, CT, pp. 1-45. 


\section{Veterinary Questions}

The therapeutic dosage for many drugs (like sedatives and antibiotics) depends on a certain percentage of the drug being bound to proteins in the blood stream and the rate at which the drug is eliminated from the blood, by the body's filtration systems (primarily kidneys and liver). In patients with diseases that lead to hypoproteinemia (abnormally low blood protein), the dosage of the drugs needs to be adjusted to ensure safety and efficacy (how well the drug works). Using your knowledge of blood physiology and waste elimination choose the best answer to the following question. If you did not adjust the dosage, but used the drugs at their normal dosage, what situation would you be most likely to encounter in hypoproteinemic patients?

a. There would be more drug molecules floating free in the blood, diffusing out to tissues more and overwhelming of the body's filtration systems, and thus leading to a potential overdose situation.

b. There would be more drug molecules floating free in the blood, but they would not diffuse out to the tissues faster and would just be eliminated by the body's filtration system faster, thus the drugs would work at the same level of efficacy, but for a shorter period of time.

c. There would be more drug molecules floating free in the blood, so they would diffuse out to tissues faster and be eliminated from the body faster, leading to an under-dosing situation.

d. There would be more drug molecules floating free in the blood, but they would not diffuse out to the tissues faster and would be most likely eliminated by the body's filtration system at the same rate, thus the drugs would work at the same level of efficacy, but for a longer period of time.

Correct Answer: A 
You walk into a surgical suite to check on an anesthetized patient. You ask your staff member, who is monitoring the patient, how the patient is doing under anesthesia. She tells you that the patient is stable, and she knows this because she keeps checking the patient's heart rate. You are concerned because monitoring only heart rate does not give you enough information about your patient. You patiently give your staff member a basic explanation of cardiovascular physiology. Choose the one statement that most correctly describes what is occurs in the cardiovascular system of your patient.

a. As long as the patient is breathing, the heart rate isn't very important, because the tissue will be perfused.

b. The kidneys are directly responsible for controlling blood pressure through glomelular filtration rate, so it is more important to monitor them then it is the heart rate.

c. Because the heart is a pump, the rate is not the only factor affecting tissue perfusion and oxygenation, the degree to which the chambers fill and the volume of the system they are pumping into is also important.

d. The build-up of $\mathrm{CO} 2$ controls the heart rate, so as long as the percentage of $\mathrm{O} 2$ going into the patient's lungs is appropriate, the heart rate will be appropriate to provide good tissue perfusion and oxygenation.

\section{Correct Answer: C}

Sick neonates often have an elevated respiratory rate, unrelated to pneumonias or primary lung problems. Use your knowledge of respiratory and cardiovascular physiology to choose the single, most accurate statement to explain the elevated respiratory rate.

a. The diseased cells produce more lactic acid, which increases the $\mathrm{pH}$, making the oxygenation-dissocation curve steeper, and increasing respiration.

b. The diseased cells produce a more alkaline environment, leading to an increased $\mathrm{pH}$, making the oxygenation-dissocation curve steeper, and increasing respiration.

c. The diseased cells need more oxygen to support their struggling cellular metabolism, thus leading to an increased demand for $\mathrm{O} 2$, and an increased respiration rate.

d. The diseased cells produce more waste products, primarily $\mathrm{CO} 2$. The respiratory system is responsible for removing excess $\mathrm{CO} 2$ from blood stream, thus leading to an increased the respiration rate.

Correct Answer: D 


\section{Questionnaire}

To construct the questionnaire the medical school instructor was approached and asked to write three additional questions. The instructor was told students were not supposed to solve the questions, but rank their confidence in the ability to answer the question. The instructor of the course wrote three questions. From this pool of questions, two were selected from the medical school instructor's questions and one was selected from the course instructor's questions. The questionnaire was constructed online at surveymonkey.com. A link was emailed to the students the same day they took the pre- and post-tests. Students were asked to rank their confidence at correctly answering the questions using a Likert scale from 1-10, where 1 is absolutely no confidence and 10 is absolute confidence. The pre-questionnaire only included the three physiology questions. The post-questionnaire also included basic demographic questions and a place for students to explain why they felt their confidences may have changed. 


\section{Questionnaire Physiology Questions}

1. Mammalian lung function is based on a balance between compliance and elastance forces. Explain the types of pulmonary changes associated with:

1) a decrease in compliance with normal elastance

2) a decrease in elastance with normal compliance

2. In a circulatory system with consistent high pressure, what might be used to regulate the pressure? What are consequences of having a consistent high pressured system?

3. Experiments in an unknown organism with radioactively labeled isotopes demonstrate preferential uptake of large quantities of $\mathrm{Ca} 2+$. What does this suggest about the organism? How might adding an aqueous solution of $\mathrm{CO} 3$ to the system affect the animal? 
If your confidence has changed between the pre- and the post-survey, please explain why you think that happened.

How do you describe yourself? (please check the one option that best describes you). If you prefer not to answer the question, please leave blank.
a) American Indian or Alaska Native
b) Hawaiian or other Pacific Islander
c) Asian or Asian American
d) Black or African American
e) Hispanic or Latino
f) Non-Hispanic White
g) Other

What is your gender? If you prefer not to answer, please leave the answer blank.
a) Male
b) Female

What is your age?

How many physiology courses have you had (please note that this is specifically describing classes in which you have had in depth coursework on systems processes, not an introductory survey such as BIOL 117)?
a) One
b) Two
c) Three
d) Four or more

What is your major?

What is your career goal?
a) Medicine
b) Veterinarian Science
c) Dentistry
d) Biomedical/Basic Research
e) Exercise Physiology
f) Other 


\section{Micah J. Waltz}

Cellular and Integrative Physiology Graduate Program

Department of Physiology and Pharmacology

School of Medicine

West Virginia University

Morgantown WV, 26505

\section{EDUCATION}

M.S. in Physiology West Virginia University, School of Medicine, Morgantown, WV 2008- 2014 Thesis: Conceptual Learning: Enhancing Student Understanding of Physiology

Advisor: M. Paternostro

Committee: R. Brock, S. Hileman,

Certification: Certificate in University Teaching

- A 15 cr. Hour Training certificate with core coursework focusing on general college as well as discipline specific pedagogy.

B.S. in Zoology Idaho State University, School of Arts and Sciences, Pocatello, ID

2004-2008 Advisor: C. Anderson

\section{RESEARCH EXPERIENCE}

Program Effectiveness

Evaluation

Spring 2014

Educational Research, Fall 2013

Research Assistant 2011-2013

Research Assistant 2009-2011
West Virginia University, School of Medicine, Morgantown, WV

Evaluation of online component of undergraduate course in a Physiology Classroom Gathered information from IT department, converted to useable data format, collated data for each individual adult learner in the course, and analyze effectiveness of individual learner pace on overall performance in the class (unit exams).

West Virginia University, School of Arts and Sciences, Morgantown, WV Curriculum Development and Evaluation for BIOL 340: Invertebrate Zoology Responsible for designing all curriculum for class, designed a course intervention using comparative physiology as a way to stimulate students ability to think about how they think. Focused students on conceptual material. Effectiveness of the intervention was evaluated using pre- and post-tests and surveys.

West Virginia University, School of Arts and Sciences, Morgantown WV

S. Farris/J. Belanger labs, Neuroanatomy/Neuroethology, Depts. of Biology,/Physiology and Pharmacology

Studying the coupling of mechanosensation with motor outputs through neural tract tracing in a central complex in Manduca sexta.

National Institute of Occupational Health (NIOSH), Morgantown WV A. Shvedova lab, Pulmonary Toxicology, Dept. of Physiology and Pharmacology Studied experimental pathology of single-walled carbon nanotubes (SWCNTs) in vitro to ascertain the regulatory effects of osteopontin (OPN) on transforming growth factor beta 1 (TGF- $\beta 1$ ). 
Laboratory Assistant Emory University, School of Arts and Sciences, Atlanta, GA

Spring 2009

D. Jones lab, Nutrition

$03 / 16-03 / 20$

Worked as a lab asssistant during spring break under the observation of a senior doctoral candidate. Analyzed previously gathered data on complex fluids and isolated potential amino acids for pairings in complex fluid analysis via MSMALDI.

Laboratory Rotation Spring 2009

West Virginia University, School of Medicine, Morgantown WV C. Buetefisch lab, Human Performance, Dept. of Physiology and Pharmacology Created map of trajectories on a Talaraich brain, positioned regions of interest (ROIs) on corpus callosum images and assisted in trans-cranial magnetic stimulation (TMS) experiments

Laboratory Rotation Summer 2008

West Virginia University, School of Medicine, Morgantown WV J. Lewis Lab, Human Perception, Dept. of Physiology and Pharmacology Worked on experimental design continuing project testing 3D spatial auditory maps and how the brain constructs them with visualization from function magnetic resonance imaging (fMRI).

Lab Technician

Idaho State University, School of Arts and Sciences, Pocatello, ID 2007-2008 Stream Ecology Center, Riparian Impact Studies, Dept. of Biological Sciences Processed riparian water samples for aquatic and terrestrial invertebrates, performed taxonomic identification, ran statistical population studies, and collected field samples.

Undergrad Research 2005-2008

Idaho State University, School of Arts and Sciences, Pocatello, ID C. Anderson lab, Frog Feeding Kinematics, Dept. of Biological Sciences Studied changes on motor nuclei with correlated body size from evolutionary perspective.

\section{PUBLICATIONS}

2012 Murray, AR; Kisin, E; Inman, A; Young, S; Muhammed, M; Burks, T; Uheida, A; Tkach, A; Waltz, M; Castranova, V; Fadeel, B; Kagan, VE; Riviere, JE; Monteiro-Riviere, N; Shvedova, AA. Oxidative Stress and Dermal Toxicity of Iron Oxide Nanoparticles In Vitro. Cell Biochem Biophys. Epub. PMID: 22669739.

\section{PRESENTATIONS/ABSTRACTS}

Waltz M.J. ${ }^{1}$, Belanger J.H. ${ }^{2}$

Sound Reception in Crabs: Keeping an ear to the ground and a leg to the wind. Dept of Physiology and Pharmacology ${ }^{1}$, WVU; Dept of Biology, WVU ${ }^{2}$

Society for Neuroscience (SfN). 10/13/12-10/17/12

West Virginia University, School of Medicine, Morgantown, WV

Keeping an Ear to the Ground: How Crabs Listen.

Departmental seminar presenting current research in the Belanger lab. 
Waltz M.J. ${ }^{1,2}$, Murray A. ${ }^{1,2}$, , Kisin E. ${ }^{2}$, Tkach A. ${ }^{2}$, Shvedova A. ${ }^{1,2}$

"Osteopontin and TGF- $\beta 1$ release in response to single walled carbon nanotube exposure."

West Virginia University ${ }^{1}$; NIOSH $^{2}$

Van Liere Research Day, WVU, 03/11/11

Waltz M.J. ${ }^{1,2}$, Murray A. ${ }^{1,2}$, Kisin E. ${ }^{2}$, Tkach A. ${ }^{2}$, Shvedova A. ${ }^{1,2}$

"Osteopontin and TGF- $\beta 1$ release in response to single walled carbon nanotube exposure."

West Virginia University ${ }^{1}$; $\mathrm{NIOSH}^{2}$

Society of Toxicology (SOT). 03/06/11-03/10/11

West Virginia University, School of Medicine, Morgantown, WV

Interplay of Osteopontin (OPN) and transforming growth factor beta 1 (TGF- $\beta 1$ ) in SWCNT induced pulmonary fibrosis.

Departmental seminar presenting current research in the Shvedova lab.

2009 West Virginia University, School of Medicine, Morgantown, WV

The Functional Anatomy of the Corpus Callosum and its Role in Motor Performance

Presented a literature search to compare models of isolating ROIs in the corpus callosum as well as its evolution, anatomy, and physiology.

Idaho State University, School of Arts and Sciences, Pocatello, ID

Neurological Compensations for Increases in Body Size

Presented research protocols for neuroanatomy of feeding kinematics with emphasis on microscopy techniques.

Idaho State University, School of Arts and Sciences, Pocatello, ID

The Problem of Growing Up

Presented research on the neuroanatomy of allometry to fellow graduate students for analysis and suggestions on theory and background of research

Waltz, Micah J. ${ }^{1}$; Blanchard, Jordan ${ }^{2}$; Anderson, Curt W. ${ }^{1}$

"The Role of Body Size and Motor Neuron Size in the Control of

Ballistic Tongue Muscle Movements."

Idaho State University ${ }^{1}$; BYU Idaho ${ }^{2}$

Society of Integrative and Comparative Biology (SICB). 01/4/07-01/09/07.

Waltz, Micah J. ${ }^{1}$; Blanchard, Jordan ${ }^{2}$; Anderson, Curt W. ${ }^{1}$

"The Role of Body Size and Motor Neuron Size in the Control of Ballistic Muscle Movements."

Snake River Association for Neuroscience Conference, 08/28/06-08/30/06.

Idaho State University, School of Arts and Sciences, Pocatello, ID

Undergraduate Colloqium

Waltz, Micah J.

"The Effects of Motor Neuron Size on Muscle Function During Prey Capture in Toads" 

Waltz, Micah J. ${ }^{1}$; Tanner Ben W. ${ }^{2}$; Anderson, Curt W. ${ }^{1}$

"The Role of Body and Neuron Scaling in Prey Capture Kinematics of Four Species of Frogs."

08/09/05-08/12/05

Idaho State University, School of Arts and Sciences, Pocatello, ID

INBRE Summer Fellowship

The Evolution and Allometry of Motor Neuron Size

Presented to fellow INBRE members and mentors the correlation between the kinematics of feeding behaviors and the allometry of neuroanatomy found over summer internship in Anderson Lab.

\section{TEACHING AND MENTORING EXPERIENCE}

Lecturer

Lab Manager

Curriculum Designer

Fall 2013

Guest Lecturer

Spring 2013

Guest Lecturer

Fall 2012

Peer Leader

Fall 2012/Spring 2013

Guest Lecturer

Fall 2012

Teaching Assistant Fall 2012/2011
West Virginia University, Eberly School of Arts and Sciences, Morgantown, WV Biology 340: Invertebrate Zoology

Instructional designer, instructor and lab manager for course. Responsible for creating and updating course website, weekly training for teaching assistant so he could teach adult learners in lab (Trained teaching assistant to design instructional material for second half of lab component), maintaining lab budget, ordering weekly supplies for lab, writing and administering content, designing and administering assessments.

West Virginia University, Eberly School of Arts and Sciences, Morgantown, WV Biology 438: Animal Behavior

Guest lecturer for two weeks grading student presentations, teaching reptile chemoreception and volmerolfaction, and discussing anthropomorphizing animal behavioral data during data analysis.

West Virginia University, School of Medicine, Morgantown, WV Physiology 441: Mechanism of Body Function Guest lecturer for reproduction, birth, and parturition.

West Virginia University, School of Medicine, Morgantown, WV PCOL 760: Medical Pharmacology

Acting small group facilitator, responsibilities are ensuring groups of medical students interact with each other using Team Based Learning (TBL) exercise, observe and report on how the students' teamwork changed over the course of a year.

West Virginia University, Eberly School of Arts and Sciences, Morgantown, WV Biology 340: Invertebrate Zoology

Guest lecturer for one week teaching Phyla Porifera(Sponges) and

Cnidaria(Jellyfish), taught students how to use taxonomic keys.

West Virginia University, Eberly School of Arts and Sciences, Morgantown WV BIOL 115: Introductory Biology for Majors

Responsible for two lab sections of 25 students each, giving introductory lectures for labs and modeling and facilitating problem based learning through experiments. Exam proctor. 
Teaching Assistant

Spring 2012

Teaching Assistant

Spring 2012

Teaching Assistant

Spring 2012

Teaching Assistant

Fall 2011

Certificate

Summer 2011

Tutor

2011- 2012

Function

Teaching Practicum Spring 2011

Tutor

2006-2008
West Virginia University, School of Medicine, Morgantown, WV

Physiology 241:Elementary Physiology

Guest lecturer: 4 lectures on reproductive system; Exam proctor

West Virginia University, Eberly School of Arts and Sciences, Morgantown, WV BIOL 117: Introductory Physiology (Lab section)

Responsible for assisting in development of semester curriculum for labs, designing experiments for sections to use, scheduling assignments, updating syllabus, and training fellow graduate students.

West Virginia University, Eberly School of Arts and Sciences, Morgantown, WV BIOL 117: Introductory Physiology

Responsible for one lab section of 25 students, giving introductory lectures for Labs, modeling and facilitating problem based learning through three modules. Exam proctor

West Virginia University, School of Medicine, Morgantown, WV

Physiology 441: Mechanisms of Body Function

Ran review sessions for students

West Virginia University Summer Institute for Undergraduate Scientific

Teaching

West Virginia University, School of Medicine, Morgantown WV

Physiology 241: Elementary Physiology; Physiology 441: Mechanisms of Body

West Virginia University, School of Medicine, Morgantown WV

Teaching Practicum, Dept. of Physiology and Pharmacology

Discipline specific course designed to teach graduate students how to prepare and give effective lectures and write effective test questions.

Idaho State University, School of Arts and Sciences, Pocatello, ID

Content Area Tutoring program

Tutored introductory biology courses for traditional and non-traditional students, as well as athletes.

Undergrad Research Idaho State University, School of Arts and Sciences, Pocatello, ID

2005-2008

Anderson Lab, Dept. of Biological Sciences

Trained PhD student and MS students in videographical and surgical techniques.

Tutor

2006-2007
Content Area Tutoring (CAT) certifications at Idaho State University

- Biology

- Cell Biology 


\section{LICENSING/CERTIFICATION}

2011

West Virginia University, School of Arts and Sciences, Dept. of Biology

American Heart Association

GRANT WRITING

Certification: First Aid, CPR

2012

WVU Workshop on Writing Successful Grants

2009 WVU Graduate Course in Grant Writing

2006 ISU UnderGraduate Research(UGRC) Committee Travel grant

Wrote and was awarded grant for funding to present research at SICB

2006 ISU UGRC Research grant S06-R2, \#691-080-01

Wrote and awarded research grant to fund studies in Anderson lab of motor nuclei change with increasing body size

\section{PROFESSIONAL SERVICE}

2013-2014 Cellular and Integrative Physiology Graduate Program Journal Club Student Leader

2013 Graduate Student Career Day

Panel moderator for discussion on post-docs: finding them, obtaining them, and succeeding in them.

$2012 \quad$ Proposal for Nanosymposium on Active Learning

Experimental Biology, San Francisco

2011-2012 Biology Graduate Student Association

Co-Social Coordinator

HONORS AND AWARDS

SICB undergraduate presenter grant ASISU Undergraduate Scholarship Idaho Promise Scholarship

Robert E. Stitzel Travel Award
Kasiska Health Scholarship

INBRE Summer Fellowship

John and Jeanne Volker Scholarship

\section{PROFESSIONAL ORGANIZATIONS/AFFILIATIONS}

2010 - 2014 Cell Biology Training Program, West Virginia University, School of Medicine, Morgantown WV

2012 - current American Physiological Society

2013 - current Sigma Xi 2013 